\title{
Discovery of Thanafactin A, a Linear Proline-containing Octa- Lipopeptide from Pseudomonas sp. SH-C52, Motivated by Genome Mining
}

Norbert Kirchner, Carolina Cano-Prieto, Anna-Christina Schulz-Fincke, Michael Gütschow,

Nico Ortlieb, Julia Moschny, Timo H. J. Niedermeyer, Jeannie Horak, Michael Lämmerhofer, Menno van der Voort, Jos M. Raaijmakers, Harald Gross

\section{SUPPORTING INFORMATION}

\section{Table of Contents}

\section{Bioinformatics and genetic data}

Figure S1 Whole genome sequence-based GBDP tree

Table S1 Pairwise dDDH comparisons (SH-C52 and DSM 11579 vs. type strain genomes)

Table S2 Analysis of the SH-C52 genome for secondary metabolite gene clusters

Figure S2 Evidence for the fusion of contig 239 and 332

Table S3 Genetic context and features of the thf BGC in P. sp. SH-C52

Table S4 Genetic context and features of the thf BGC in P. f. DSM 11579

Figure S3 Phylogenetic A-domain analysis

Figure S4 Phylogenetic C-domain analysis

Figure S5 Phylogenetic TE-domain analysis

Table S5 List of primers used in this study

\section{Metabolite Profiling}

Figure S6 Comparative HPLC profiles of the crude extracts of the wt vs $2 \mathrm{mt}$ strains

Figure S7 HPLC-run of an upscaled cultivation batch of the DSM 11579 strain

\section{Spectral Data for Thanafactin A (1)}

Figure S8 HR-ESI-MS spectrum of 1 (positive mode).

Figure S9 UV spectrum of 1 in $\mathrm{MeOH}$

Figure S10 CD-spectrum of 1 in $\mathrm{MeOH}$

Figure S11 FT-IR spectrum of 1

Figure S12 $400 \mathrm{MHz}^{1} \mathrm{H}$ NMR spectrum of 1 in $d_{6}$-DMSO

Figure S13 $100 \mathrm{MHz}{ }^{13} \mathrm{C}$ NMR spectrum of 1 in $d_{6}$-DMSO

Figure S14 $400 \mathrm{MHz}$ DEPT135 NMR spectrum of 1 in $d_{6}$-DMSO

Figure S15 $\quad 400 \mathrm{MHz}^{1} \mathrm{H}_{-}{ }^{13} \mathrm{C}$ HSQC NMR spectrum of 1 in $d_{6}$-DMSO

Figure S16 $400 \mathrm{MHz}^{1} \mathrm{H}^{1}{ }^{1} \mathrm{H}$ COSY NMR spectrum of 1 in $d_{6}$-DMSO

Figure S17 $400 \mathrm{MHz}{ }^{1} \mathrm{H}_{-}{ }^{13} \mathrm{C}$ HSQC-TOCSY NMR spectrum of 1 in $d_{6}$-DMSO

Figure S18 MS/MS analysis of 1

Determination of the Absolute Configuration of Thanafactin A (1)

Figure S19 Determination of the absolute configuration of 3-HDA of 1

Figure S20 Enantioselective GC-MS analysis of the peptide hydrolysate of thanafactin A

\section{Bioassay data}

Figure S21 Swarming assays

Table S6 Protease inhibition assay 
Figure S1. Whole genome sequence-based Genome BLAST Distance Phylogeny (GBDP) tree

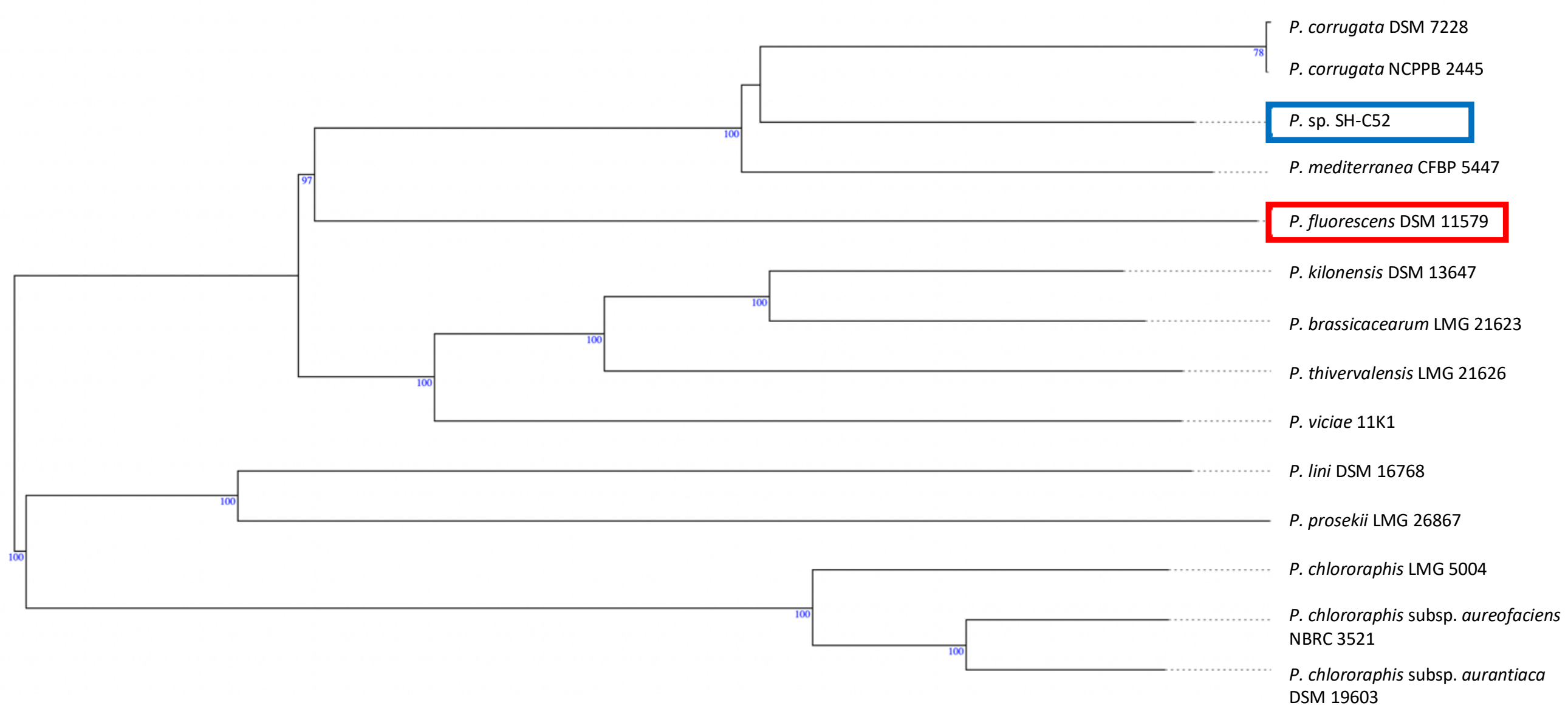


Table S1. Pairwise dDDH comparisons of the SH-C52 and DSM 11579 genomes vs. type strain genomes.

\begin{tabular}{|c|c|c|c|c|c|c|c|c|}
\hline Query strain & Subject strain & $\begin{array}{l}\text { dDDH } \\
\left(d_{0}, \text { in }\right. \\
\%)\end{array}$ & $\begin{array}{l}\text { c.l. } \\
\left(d_{0},\right. \\
\text { in \%) }\end{array}$ & $\begin{array}{l}\text { dDDH } \\
\left(d_{4} \text {, in }\right. \\
\%)\end{array}$ & $\begin{array}{l}\text { C.I. } \\
\text { (d } d_{4}, \\
\text { in \%) }\end{array}$ & $\begin{array}{l}\text { dDDH } \\
\left(d_{6} \text {, in }\right. \\
\%)\end{array}$ & $\begin{array}{l}\text { C.I. } \\
\text { (d } \mathbf{d}_{6}, \\
\text { in \%) }\end{array}$ & $\begin{array}{l}\text { G+C content } \\
\text { difference (in } \\
\% \text { ) }\end{array}$ \\
\hline $\begin{array}{l}\text { 'Pseudomonas sp. SHC52' } \\
\text { (CBLV00000000) }\end{array}$ & $\begin{array}{l}\text { Pseudomonas mediterranea CFBP } \\
5447\end{array}$ & 79.1 & $\begin{array}{l}{[75.2-} \\
82.6]\end{array}$ & 52.9 & $\begin{array}{l}{[50.3-} \\
55.6]\end{array}$ & 75.9 & $\begin{array}{l}{[72.4-} \\
79.0]\end{array}$ & 0.26 \\
\hline $\begin{array}{l}\text { 'Pseudomonas sp. SHC52' } \\
\text { (CBLV00000000) }\end{array}$ & $\begin{array}{l}\text { Pseudomonas corrugata NCPPB } \\
2445\end{array}$ & 77.1 & $\begin{array}{l}{[73.1-} \\
80.6]\end{array}$ & 51.7 & $\begin{array}{l}{[49.0-} \\
54.3]\end{array}$ & 73.8 & $\begin{array}{l}{[70.3-} \\
77.0]\end{array}$ & 0.35 \\
\hline $\begin{array}{l}\text { 'Pseudomonas sp. SHC52' } \\
\text { (CBLV00000000) }\end{array}$ & Pseudomonas corrugata DSM 7228 & 76.9 & $\begin{array}{l}{[72.9-} \\
80.5]\end{array}$ & 51.5 & $\begin{array}{l}{[48.9-} \\
54.2]\end{array}$ & 73.6 & $\begin{array}{l}{[70.1-} \\
76.8]\end{array}$ & 0.36 \\
\hline $\begin{array}{l}\text { 'Pseudomonas sp. SHC52' } \\
\text { (CBLV00000000) }\end{array}$ & $\begin{array}{l}\text { Pseudomonas kilonensis DSM } \\
13647\end{array}$ & 52.0 & $\begin{array}{l}{[48.5-} \\
55.5]\end{array}$ & 34.3 & $\begin{array}{l}{[31.9-} \\
36.8]\end{array}$ & 47.4 & $\begin{array}{l}{[44.4-} \\
50.4]\end{array}$ & 0.11 \\
\hline $\begin{array}{l}\text { 'Pseudomonas sp. SHC52' } \\
\text { (CBLV00000000) }\end{array}$ & $\begin{array}{l}\text { Pseudomonas brassicacearum LMG } \\
21623\end{array}$ & 55.3 & $\begin{array}{l}{[51.7-} \\
58.8]\end{array}$ & 34.2 & $\begin{array}{l}{[31.8-} \\
36.7]\end{array}$ & 49.8 & $\begin{array}{l}{[46.8-} \\
52.9]\end{array}$ & 0.17 \\
\hline $\begin{array}{l}\text { 'Pseudomonas sp. SHC52' } \\
\text { (CBLV00000000) }\end{array}$ & $\begin{array}{l}\text { Pseudomonas thivervalensis LMG } \\
21626\end{array}$ & 54.3 & $\begin{array}{l}{[50.8-} \\
57.8]\end{array}$ & 33.6 & $\begin{array}{l}{[31.1-} \\
36.1]\end{array}$ & 48.8 & $\begin{array}{l}{[45.8-} \\
51.9]\end{array}$ & 0.22 \\
\hline $\begin{array}{l}\text { 'Pseudomonas fluorescens' } \\
\text { (JAAOIQ000000000) }\end{array}$ & $\begin{array}{l}\text { Pseudomonas kilonensis DSM } \\
13647\end{array}$ & 52.6 & $\begin{array}{l}{[49.1-} \\
56.0]\end{array}$ & 33.5 & $\begin{array}{l}{[31.1-} \\
36.0]\end{array}$ & 47.5 & $\begin{array}{l}{[44.5-} \\
50.6]\end{array}$ & 0.9 \\
\hline $\begin{array}{l}\text { 'Pseudomonas sp. SHC52' } \\
\text { (CBLV000000000) }\end{array}$ & Pseudomonas viciae $11 \mathrm{~K} 1$ & 54.1 & $\begin{array}{l}{[50.6-} \\
57.6]\end{array}$ & 33.4 & $\begin{array}{l}{[31.0-} \\
35.9]\end{array}$ & 48.6 & $\begin{array}{l}{[45.6-} \\
51.7]\end{array}$ & 0.64 \\
\hline $\begin{array}{l}\text { 'Pseudomonas fluorescens' } \\
\text { (JAAOIQ000000000) }\end{array}$ & $\begin{array}{l}\text { Pseudomonas brassicacearum LMG } \\
21623\end{array}$ & 54.8 & $\begin{array}{l}{[51.2-} \\
58.2]\end{array}$ & 33.3 & $\begin{array}{l}{[30.9-} \\
35.8]\end{array}$ & 49.1 & $\begin{array}{l}{[46.0-} \\
52.1]\end{array}$ & 0.97 \\
\hline $\begin{array}{l}\text { 'Pseudomonas fluorescens' } \\
\text { (JAAOIQ000000000) }\end{array}$ & $\begin{array}{l}\text { Pseudomonas thivervalensis LMG } \\
21626\end{array}$ & 54.2 & $\begin{array}{l}{[50.6-} \\
57.6]\end{array}$ & 32.9 & $\begin{array}{l}{[30.5-} \\
35.4]\end{array}$ & 48.5 & $\begin{array}{l}{[45.4-} \\
51.5]\end{array}$ & 0.57 \\
\hline $\begin{array}{l}\text { 'Pseudomonas sp. SHC52' } \\
\text { (CBLV00000000) }\end{array}$ & $\begin{array}{l}\text { 'Pseudomonas fluorescens' } \\
\text { (JAAOIQ000000000) }\end{array}$ & 56.7 & $\begin{array}{l}{[53.2-} \\
60.2]\end{array}$ & 32.7 & $\begin{array}{l}{[30.3-} \\
35.2]\end{array}$ & 50.3 & $\begin{array}{l}{[47.2-} \\
53.3]\end{array}$ & 0.79 \\
\hline $\begin{array}{l}\text { 'Pseudomonas fluorescens' } \\
\text { (JAAOIQ000000000) }\end{array}$ & $\begin{array}{l}\text { Pseudomonas mediterranea CFBP } \\
5447\end{array}$ & 59.7 & $\begin{array}{l}{[56.0-} \\
63.2]\end{array}$ & 32.7 & $\begin{array}{l}{[30.3-} \\
35.2]\end{array}$ & 52.5 & $\begin{array}{l}{[49.4-} \\
55.5]\end{array}$ & 0.53 \\
\hline $\begin{array}{l}\text { 'Pseudomonas fluorescens' } \\
\text { (JAAOIQ000000000) }\end{array}$ & Pseudomonas viciae $11 \mathrm{~K} 1$ & 56.3 & $\begin{array}{l}{[52.7-} \\
59.8]\end{array}$ & 32.5 & $\begin{array}{l}{[30.1-} \\
35.1]\end{array}$ & 49.9 & $\begin{array}{l}{[46.8-} \\
53.0]\end{array}$ & 1.43 \\
\hline $\begin{array}{l}\text { 'Pseudomonas fluorescens' } \\
\text { (JAAOIQ000000000) }\end{array}$ & Pseudomonas corrugata DSM 7228 & 59.7 & $\begin{array}{l}{[56.0-} \\
63.2]\end{array}$ & 32.1 & $\begin{array}{l}{[29.6-} \\
34.6]\end{array}$ & 52.1 & $\begin{array}{l}{[49.0-} \\
55.2]\end{array}$ & 1.15 \\
\hline $\begin{array}{l}\text { 'Pseudomonas fluorescens' } \\
\text { (JAAOIQ000000000) }\end{array}$ & $\begin{array}{l}\text { Pseudomonas corrugata NCPPB } \\
2445\end{array}$ & 59.6 & $\begin{array}{l}{[56.0-} \\
63.2]\end{array}$ & 32.0 & $\begin{array}{l}{[29.6-} \\
34.5]\end{array}$ & 52.1 & $\begin{array}{l}{[49.0-} \\
55.1]\end{array}$ & 1.14 \\
\hline
\end{tabular}

Table S2. Secondary metabolite gene clusters identified in Pseudomonas sp. SH-C52 by genome mining.

\begin{tabular}{llll}
\hline Cluster & Contig & Type & Predicted product \\
\hline 1 & 47 & NRPS (tri-modular) & unknown \\
2 & 54 & NRPS (mono-modular) & Unknown (Fragin-like) \\
3 & 74 & Siderophore (iucA/C) & Achromobactin \\
4 & 178 & B-keto-Acyl-Synthase & Arylpolyene \\
5 & 210 & NRPS (standalone domains) & unknown \\
6 & 239 & NRPS (penta-modular) & Thanafactin part I \\
7 & 242 & NRPS (3-modular) & unknown \\
8 & 266 & Bacteriocin & unknown \\
9 & 317 & NRPS (standalone domains) & unknown \\
10 & 330 & NRPS (22-modular) & Thanapeptin \\
11 & 330 & NRPS (octa-modular) & Thanamycin \\
12 & 330 & NRPS (bi-modular) & Brabantamide \\
13 & 332 & NRPS (tri-modular) & Thanafactin part II \\
14 & 352 & Other (mgo BGC) & no product (incomplete) \\
\hline
\end{tabular}


Figure S2. (A) PCR-evidence for the fusion of cluster 6 and 13, located on contig 239 and 332, respectively. Agarose gel (2.5\%) electrophoresis of the PCR to join the gene cluster 6 and 13 . M1 Marker 25 bp of Bioline. C-: Negative control $\left(\mathrm{H}_{2} \mathrm{O}\right)$. R1: Replication 1 with gDNA of Pseudomonas sp. SH-C52. R2: Replication 2 with gDNA of Pseudomonas sp. SH-C52. M2: Marker $21 \mathrm{~Kb}$ of Bioline. (B) Alignment to determine the missing sequence (red) between the end of contig 239 (blue), the start of contig 332 (blue) and the PCR product obtained with the primers $\mathrm{SH}-\mathrm{C} 52 \mathrm{NN}$ fw/rv (green).

(A)
M1
C-
R1
R2
$\mathrm{M} 2$

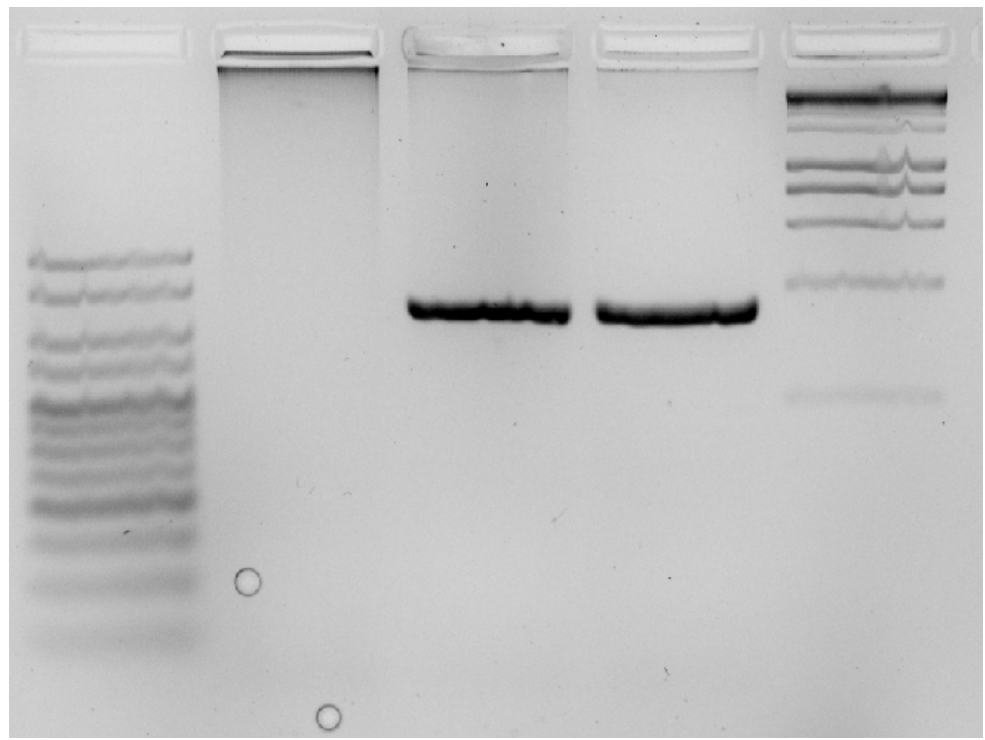

(B)

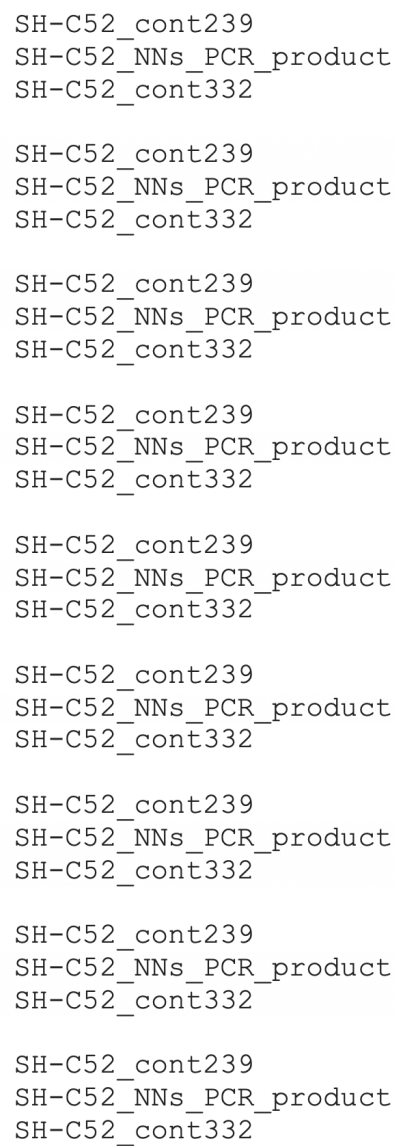

CTCAAAGCTCTGCCTGGAATCACCGAAGCGGTGGTGCGGGTCGATGCCCAACAGCGCCTG 60 CAAAGC

CTCGCCTATTTCAGCGCGCCCGAGACTCAACAGCCCAACGAACTGCGGGCCCGCTTGGCC 12

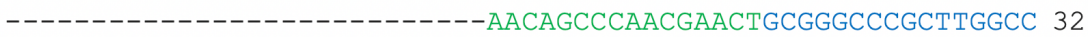

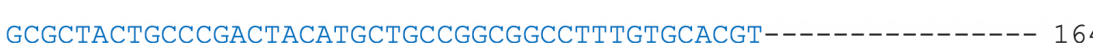
GCGCTACTGCCCGACTACATGCTGCCGGCGGCCTTTGTGCACGTGGAAGCTTTTAGCCTG 92

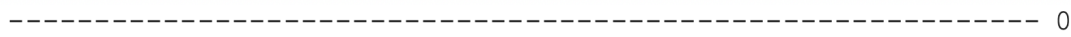

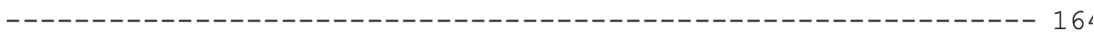
ACCGCCAACGGCAAGCTCGACCGCCGCGCCCTGCCCGAGCCCAGTGAAAACCATTTCGCC 15:
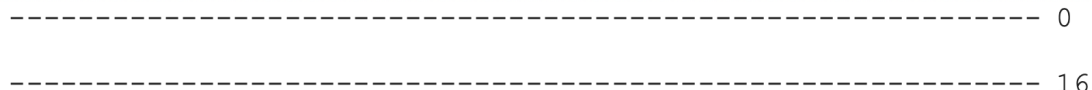
CTGCAGCGCTACGAAGCTCCCGAGCGGCCGGTGGAAAGTCGCCTCGCCGAGCTCTGGGCG 21:

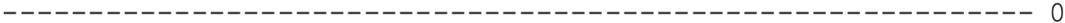

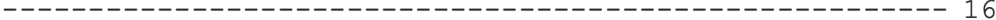
CAAACCCTCGGCGTGCCGCGGGTGGGACGCCAGGACAATTTCTTTGCCCTGGGCGGGCAT 27:

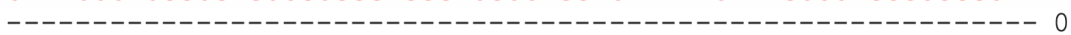

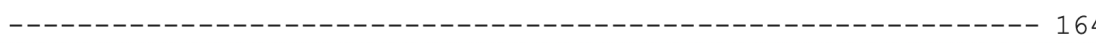
TCGCTGCTGGCGGTGCAGTTGGTCGAGCAGCTGCGGGTGGACGGTTGGGCCATCGATGTA 33 ------CTGGCGGTGCAGTTGGTCGAGCAGCTGCGGGTGGACGGTTGGGCCATCGATGTA 54

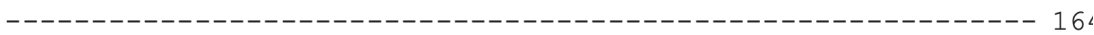

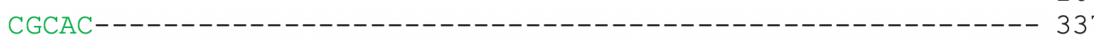
CGCACCCTGTTCGGCGCCCCCACGGTCGGCGCACTCGCGGCGATCCTGACCGAACACGGC 11 ،

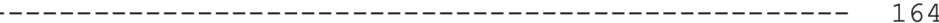

GAGGCACCGGCCGATGCCCTTGACGTACCCGGCGGTCCCTTGCCGGCGGG 164 
Table S3. Genetic context and features of the thf BGC in P. sp. SH-C52.

\begin{tabular}{|c|c|c|c|c|}
\hline Gene & Accession number & $\mathrm{Aa}$ & Proposed function & \%Homology/\%similarity \\
\hline orf-1 & WP_041022816.1 & 163 & Alcohol dehydrogenase & $\begin{array}{l}\text { Pseudomonas sp. } \\
\text { ICMP22404 99/98.16 }\end{array}$ \\
\hline orf-2 & & 40 & Hypothetical protein & Pseudomonas spp. 56/48 \\
\hline orf-3 & WP_041022817.1 & 290 & $\begin{array}{l}A B C \text { transporter substrate- } \\
\text { binding protein }\end{array}$ & $\begin{array}{l}\text { Pseudomonas sp. } \\
\text { ICMP22404 99/97 }\end{array}$ \\
\hline orf-4 & WP_041022818.1 & 267 & $\begin{array}{l}\text { ABC transporter permease } \\
\text { subunit }\end{array}$ & $\begin{array}{l}\text { Pseudomonas sp. } \\
\text { ICMP22404 99/98 }\end{array}$ \\
\hline orf-5 & WP_041022819.1 & 279 & $\begin{array}{l}\text { ATP-binding cassette domain- } \\
\text { containing protein }\end{array}$ & $\begin{array}{l}\text { Pseudomonas sp. } \\
\text { ICMP22404 99/98 }\end{array}$ \\
\hline orf-6 & WP_052435132.1 & 290 & alpha/beta hydrolase & $\begin{array}{l}\text { Acidobacteria bacterium } \\
89 / 43\end{array}$ \\
\hline orf-7 & WP_156996917.1 & 434 & hypothetical protein & $\begin{array}{l}\text { Pseudomonas } \\
\text { brassicacearum } 83 / 70\end{array}$ \\
\hline orf-8 & CDF95144.1/WP_052435139.1 & 434 & OprD family porin & $\begin{array}{l}\text { Pseudomonas } \\
\text { brassicacearum } 95 / 77\end{array}$ \\
\hline orf-9 & CDF95145.1/WP_156996921.1 & 476 & MFS transporter & $\begin{array}{l}\text { Pseudomonas argentinensis } \\
95 / 80\end{array}$ \\
\hline orf-10 & WP_041022824.1 & 425 & $\begin{array}{l}\text { FAD-dependent } \\
\text { oxidoreductase }\end{array}$ & $\begin{array}{l}\text { Pseudomonas flavescens } \\
\text { 99/85 }\end{array}$ \\
\hline orf-11 & WP_041022825.1 & 567 & dihydroxy-acid dehydratase & $\begin{array}{l}\text { Pseudomonas argentinensis } \\
99 / 90\end{array}$ \\
\hline orf-12 & WP_052435135.1 & 335 & $\begin{array}{l}\text { LysR family transcriptional } \\
\text { regulator }\end{array}$ & $\begin{array}{l}\text { Pseudomonas flavescens } \\
92 / 83\end{array}$ \\
\hline thfA & WP_052435136.1 & 3215 & $\begin{array}{l}\text { NRPS amino acid adenylation } \\
\text { domain-containing protein }\end{array}$ & $\begin{array}{l}\text { Pseudomonas sp. S58 } \\
86 / 94\end{array}$ \\
\hline $\operatorname{thfB}$ & WP_156996969.1 & 5932 & $\begin{array}{l}\text { NRPS amino acid adenylation } \\
\text { domain-containing protein }\end{array}$ & $\begin{array}{l}\text { Pseudomonas sp. } \\
\text { ICMP22404 99/95 }\end{array}$ \\
\hline thfC & WP_084213815.1 & 454 & MFS transporter & $\begin{array}{l}\text { Pseudomonas sp. } \\
\text { ICMP22404 95/96 }\end{array}$ \\
\hline orf +1 & WP_041024241.1 & 536 & response regulator & $\begin{array}{l}\text { Pseudomonas sp. } \\
\text { ICMP22404 99/97 }\end{array}$ \\
\hline orf +2 & WP_041024242.1 & 522 & response regulator & $\begin{array}{l}\text { Pseudomonas sp. } \\
\text { ICMP22404 }\end{array}$ \\
\hline orf +3 & CDF96699.1/WP_084213817.1 & 173 & hypothetical protein & $\begin{array}{l}\text { Pseudomonas sp. } \\
\text { ICMP22404 93/98 }\end{array}$ \\
\hline orf +4 & CDF96700.1 & 82 & $\begin{array}{l}\mathrm{NAD}(\mathrm{P}) \mathrm{H} \text {-binding protein/ } \\
\text { Hyptohetical protein }\end{array}$ & $\begin{array}{l}\text { Streptomyces corchorusii } \\
45 / 52\end{array}$ \\
\hline orf +5 & WP_041024243.1 & 210 & response regulator & $\begin{array}{l}\text { Pseudomonas sp. } \\
\text { ICMP22404 99/92 }\end{array}$ \\
\hline orf +6 & CDF96701.1/WP_041024258.1 & 271 & $\begin{array}{l}\text { isocitrate } \\
\text { lyase/phosphoenolpyruvate } \\
\text { mutase family protein }\end{array}$ & $\begin{array}{l}\text { Pseudomonas sp. } \\
\text { ICMP22404 98/98 }\end{array}$ \\
\hline orf +7 & WP_156996970.1 & 145 & c-type cytochrome & $\begin{array}{l}\text { Pseudomonas sp. } \\
\text { ICMP22404 99/91 }\end{array}$ \\
\hline orf +8 & WP_041024244.1 & 425 & hypothetical protein & $\begin{array}{l}\text { Pseudomonas corrugate } \\
97 / 99\end{array}$ \\
\hline orf +9 & & 66 & $\begin{array}{l}\text { hypothetical protein } \\
\text { SAMN05216476_3378 }\end{array}$ & $\begin{array}{l}\text { Pseudomonas mediterranea } \\
55 / 97\end{array}$ \\
\hline orf +10 & CDF96704.1/WP_041024245.1 & 116 & hypothetical protein & $\begin{array}{l}\text { unclassified Pseudomonas } \\
15 / 100\end{array}$ \\
\hline
\end{tabular}


Table S4. Genetic context and features of the thf BGC in P. f. DSM 11579.

\begin{tabular}{|c|c|c|c|c|}
\hline Gene & Gene number & $\mathrm{Aa}$ & Proposed function & \% Homology/\% similarity \\
\hline orf-1 & prokka_02140 & 259 & $\begin{array}{l}\text { polar amino acid transport system } \\
\text { ATP-binding protein }\end{array}$ & $\begin{array}{l}\text { Pseudomonas sp. NFACC32-1 } \\
\text { 99/100 } \\
\text { Pseudomonas sp. SHC52 99/95 } \\
\text { WP_041024619.1 }\end{array}$ \\
\hline orf-2 & prokka_02141 & 258 & $\begin{array}{l}\text { polar amino acid transport system } \\
\text { permease protein }\end{array}$ & $\begin{array}{l}\text { Pseudomonas sp. NFACC32-1 } \\
99 / 100\end{array}$ \\
\hline orf-3 & prokka_02142 & 268 & $\begin{array}{l}A B C \text { transporter substrate-binding } \\
\text { protein }\end{array}$ & $\begin{array}{l}\text { Pseudomonas sp. NFACC36 99/96 } \\
\text { Pseudomonas sp. SHC52 99/87 } \\
\text { WP_041023080.1 }\end{array}$ \\
\hline orf-4 & prokka_02143 & 222 & $\begin{array}{l}\text { GntR family transcriptional } \\
\text { regulator }\end{array}$ & $\begin{array}{l}\text { Pseudomonas brassicacearum } \\
\text { 99/93 } \\
\text { Pseudomonas sp. SHC52 99/89 } \\
\text { WP_041023081.1 }\end{array}$ \\
\hline orf-5 & prokka_02144 & 152 & $\begin{array}{l}\text { hypothetical protein } \\
\text { SAMN03159376_01765 }\end{array}$ & $\begin{array}{l}\text { Pseudomonas sp. NFACC09-4 99/97 } \\
\text { Pseudomonas sp. SHC52 90/61 } \\
\text { WP_041022795.1 }\end{array}$ \\
\hline orf-6 & prokka_02145 & 394 & Sugar lactone lactonase YvrE [] & $\begin{array}{l}\text { Pseudomonas sp. NFACC09-4 99/99 } \\
\text { Pseudomonas sp. SHC52 98/30 } \\
\text { WP_041020880.1 }\end{array}$ \\
\hline orf-7 & prokka_02146 & 301 & $\begin{array}{l}\text { LysR family transcriptional } \\
\text { regulator }\end{array}$ & $\begin{array}{l}\text { Pseudomonas sp. NFACC09-4 } \\
\text { 99/100 } \\
\text { Pseudomonas sp. SHC52 98/54 } \\
\text { WP_041022549.1 }\end{array}$ \\
\hline orf-8 & prokka_02147 & 314 & $\begin{array}{l}\text { GlxA family transcriptional } \\
\text { regulator }\end{array}$ & $\begin{array}{l}\text { Pseudomonas sp. NFACC09-4 } \\
\text { 99/100 } \\
\text { Pseudomonas sp. SHC52 97/35 } \\
\text { WP_041024346.1 }\end{array}$ \\
\hline orf-9 & prokka_02148 & 266 & SDR family oxidoreductase & $\begin{array}{l}\text { Pseudomonas sp. NFACC09-4 99/99 } \\
\text { Pseudomonas sp. SHC52 95/49 } \\
\text { WP_041024914.1 }\end{array}$ \\
\hline orf-10 & prokka_02149 & 254 & $\begin{array}{l}\text { SDR family NAD(P)-dependent } \\
\text { oxidoreductase }\end{array}$ & $\begin{array}{l}\text { Pseudomonas sp. NFACC36 99/99 } \\
\text { Pseudomonas sp. SHC52 87/27 } \\
\text { WP_041023216.1 }\end{array}$ \\
\hline orf-11 & prokka_02150 & 67 & hypothetical protein & $\begin{array}{l}\text { Pseudomonas sp. SHC52 96/53 } \\
\text { WP_041023729.1 }\end{array}$ \\
\hline orf-12 & prokka_02151 & 176 & hypothetical protein AM274_24230 & $\begin{array}{l}\text { Pseudomonas sp. } 655 \text { 98/70 } \\
\text { Pseudomonas sp. SHC52 19/35 } \\
\text { WP_041023084.1 }\end{array}$ \\
\hline orf-13 & prokka_02152 & 348 & $\begin{array}{l}\text { class I SAM-dependent } \\
\text { methyltransferase }\end{array}$ & $\begin{array}{l}\text { Pseudomonas sp. Pf153 99/92 } \\
\text { Pseudomonas sp. SHC52 28/31 } \\
\text { WP_041022911.1 }\end{array}$ \\
\hline orf-14 & prokka_02153 & 53 & $\begin{array}{l}\text { DUF2986 domain-containing } \\
\text { protein }\end{array}$ & $\begin{array}{l}\text { Pseudomonas sp. P97.38 65/92 } \\
\text { Pseudomonas sp. SHC52 98/75 } \\
\text { WP_084213720.1 }\end{array}$ \\
\hline orf-15 & prokka_02154 & 260 & SDR family oxidoreductase & $\begin{array}{l}\text { Pseudomonas sp. PE08 97/82 } \\
\text { Pseudomonas sp. SHC52 98/77 } \\
\text { WP_041021097.1 }\end{array}$ \\
\hline thfA & prokka_02155 & 3182 & $\begin{array}{l}\text { NRPS amino acid adenylation } \\
\text { domain-containing protein }\end{array}$ & $\begin{array}{l}\text { Pseudomonas sp. 7SR1 99/99 } \\
\text { Pseudomonas sp. SHC52 99/77 } \\
\text { WP_052435136.1 }\end{array}$ \\
\hline thfB & prokka_02156 & 5938 & $\begin{array}{l}\text { NRPS amino acid adenylation } \\
\text { domain-containing protein }\end{array}$ & $\begin{array}{l}\text { Pseudomonas sp. NFACC43 90/99 } \\
\text { Pseudomonas sp. SHC52 99/79 } \\
\text { WP_156996969.1 }\end{array}$ \\
\hline
\end{tabular}




\begin{tabular}{|c|c|c|c|c|}
\hline thfC & prokka_02157 & 440 & MFS transporter & $\begin{array}{l}\text { Pseudomonas sp. NFACC49-2 } \\
\text { 99/99 } \\
\text { Pseudomonas sp. SHC52 99/78 } \\
\text { WP_084213815.1 }\end{array}$ \\
\hline$o r f+1$ & prokka_02158 & 65 & hypothetical protein & $\begin{array}{l}\text { Pseudomonas sp. NFACC49-2 } \\
\text { 92/100 } \\
\text { Pseudomonas sp. SHC52 28/47 } \\
\text { WP_041021139.1 }\end{array}$ \\
\hline orf +2 & prokka_02159 & 113 & $\begin{array}{l}\text { carboxymuconolactone } \\
\text { decarboxylase family protein }\end{array}$ & $\begin{array}{l}\text { Pseudomonas sp. NFACC36 99/99 } \\
\text { Pseudomonas sp. SHC52 99/99 } \\
\text { WP_041024123.1 }\end{array}$ \\
\hline orf +3 & prokka_02160 & 301 & $\begin{array}{l}\text { AraC family transcriptional } \\
\text { regulator }\end{array}$ & $\begin{array}{l}\text { Pseudomonas sp. NFACC49-2 99/99 } \\
\text { Pseudomonas sp. SHC52 99/76 } \\
\text { WP_041024124.1 }\end{array}$ \\
\hline orf +4 & prokka_02161 & 684 & $\begin{array}{l}2 \mathrm{Fe}-2 \mathrm{~S} \text { iron-sulfur cluster binding } \\
\text { domain-containing protein }\end{array}$ & $\begin{array}{l}\text { Pseudomonas sp. 7SR1 99/99 } \\
\text { Pseudomonas sp. SHC52 99/79 } \\
\text { WP_041023741.1 }\end{array}$ \\
\hline$o r f+5$ & prokka_02162 & 412 & OprD family porin & $\begin{array}{l}\text { Pseudomonas sp. NFACC49-2 99/98 } \\
\text { Pseudomonas sp. SHC52 97/90 } \\
\text { WP_041024426.1 }\end{array}$ \\
\hline$o r f+6$ & prokka_02163 & 325 & LysR family & $\begin{array}{l}\text { Pseudomonas sp. 7SR1 99/100 } \\
\text { Pseudomonas sp. SHC52 94/93 } \\
\text { WP_041024425.1 }\end{array}$ \\
\hline$o r f+7$ & prokka_02164 & 267 & putative hydrolyase & $\begin{array}{l}\text { Pseudomonas sp. NFACC09-4 99/99 } \\
\text { Pseudomonas sp. SHC52 99/88 } \\
\text { WP_041024424.1 }\end{array}$ \\
\hline$o r f+8$ & prokka_02165 & 187 & $\begin{array}{l}\text { SnoaL-like domain-containing } \\
\text { protein }\end{array}$ & $\begin{array}{l}\text { Pseudomonas sp. NFACC49-2 } \\
\text { 99/100 } \\
\text { Pseudomonas sp. SHC52 95/66 } \\
\text { WP 041024423.1 }\end{array}$ \\
\hline
\end{tabular}


Figure S3. Phylogenetic analysis of A-domains extracted from the resultant modules of lipopeptide gene clusters encoding synthetases involved in arthrofactin (Arf, Pseudomonas sp. strain MIS38), corpeptin (Cor, Pseudomonas corrugata NCPPB 2445), syringafactin (Sfa, Pseudomonas syringae DC3000), orfamide (Orf, Pseudomonas protegens Pf-5), putisolvin (Put, Pseudomonas putida PCL1445), viscosin (Vis, Pseudomonas fluorescens SBW25), xantholysin (Xtl, P. putida BW11M1), pyoverdine (Pvd, Pseudomonas spp.), kurstakin (Kur, Bacillus thuringiensis) and locillomycin (Loc, Bacillus subtilis 916) biosynthesis. Nonproteinogenic amino acids are annotated as follows: 2,3-dehydro-2-aminobutyric acid (Dhb) and 2,4diaminobutyric acid (Dab). A-domains of ThfA and ThfB (from P. sp. SH-C52) are designated '8aa' and are highlighted in color.

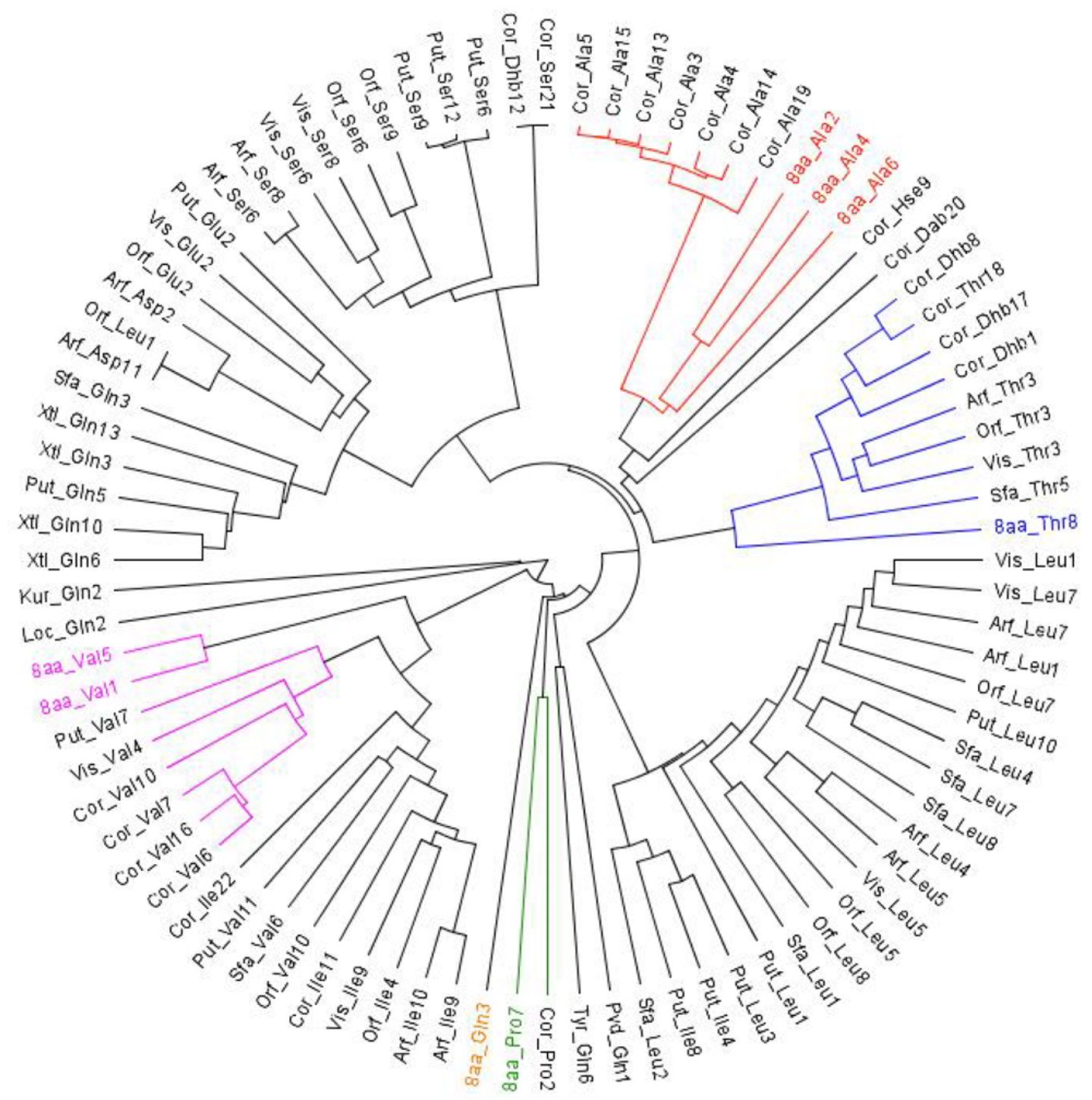


Figure S4. Phylogenetic analysis of the condensation domains of ThfA and ThfB. Reference lipopeptide BGCs encode C-domains involved in arthrofactin (Arf, Pseudomonas sp. strain MIS38), corpeptin (Cor, Pseudomonas corrugata NCPPB 2445), massetolide (Mas, $P$. fluorescens SS101), syringafactin (Sfa, Pseudomonas syringae DC3000), orfamide (Orf, Pseudomonas protegens Pf-5), poaeamide (Poe, Pseudomonas poae RE*1-1-14), viscosin (Vis, Pseudomonas fluorescens SBW25) and white-line-inducing principle WLIP (WIp, P. putida RW10S2) biosynthesis. C-domains of ThfA and ThfB (from P. sp. SH-C52) are designated '8aa' and their category is highlighted in color: conventional ${ }^{\mathrm{L}} \mathrm{C}_{\mathrm{L}}$ domains (green), dual condensation/epimerization domains (blue), and $\mathrm{N}$-acylating $\mathrm{C}_{\mathrm{S}}$ starter domains (red).

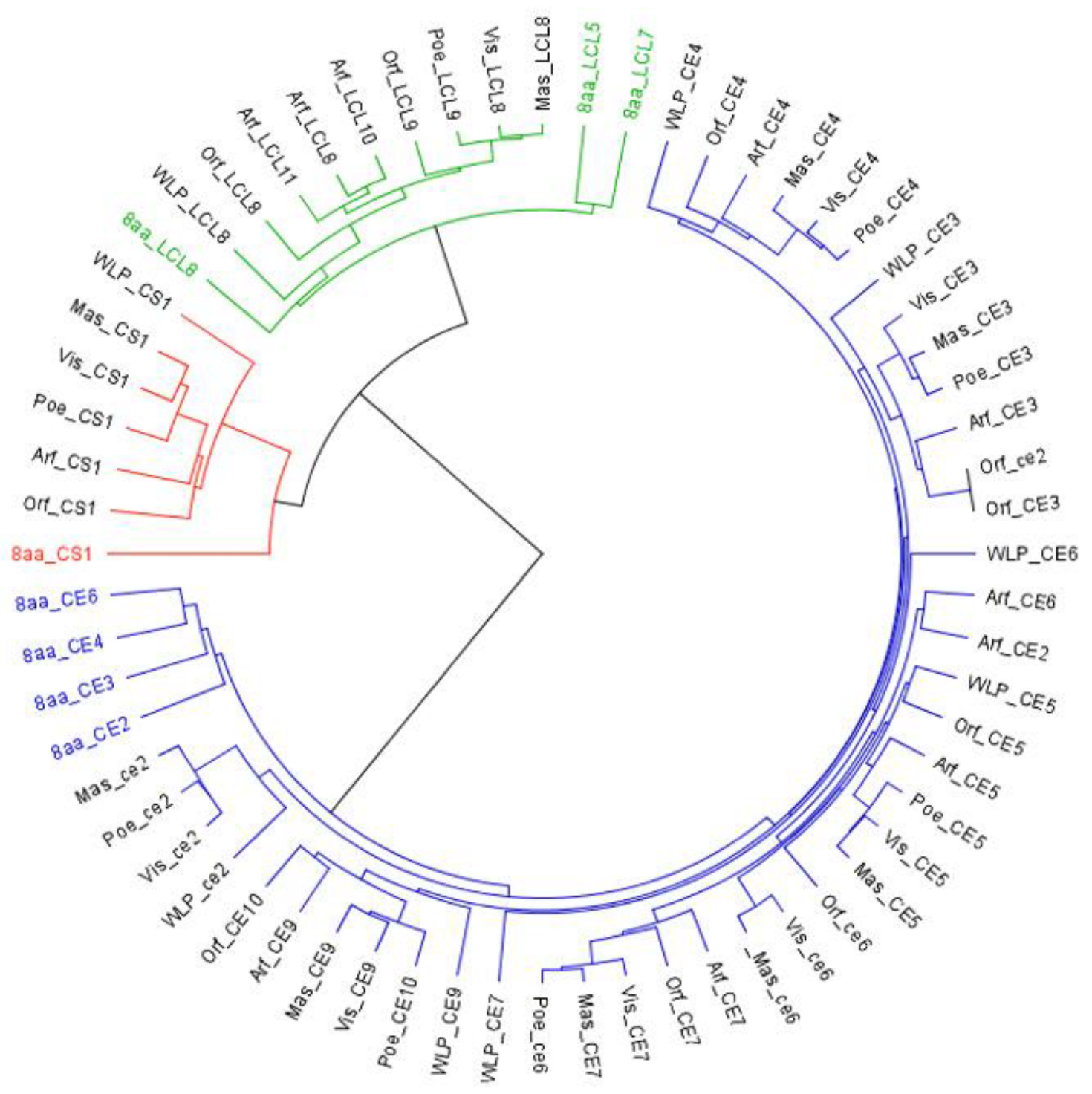


Figure S5. Phylogenetic TE-domain analysis of characterized Actinomycetes, Bacillus and Pseudomonas species. Lipopeptide-specific codes are actinomycin (Act, Streptomyces chrysomallus ATCC 11523), arthrofactin (Arf, P. sp. MIS38), bacillomycin (Bmy, B. subtilis), calcium-dependent antibiotic (CDA, Streptomyces coelicolor), daptomycin (Dapto, Streptomyces roseosporus NRRL 11379), bacillibactin (DhbF, B. subtilis), enduracidin (End, Streptomyces fungicidicus ATCC 21013), entolysin (Etl, P. entomophila L48), fengycin (Fgy, B. subtilis 168), friulimicin (Fri, Actinoplanes friuliensis HAG010964), gramicidin (Grs, B. brevis ATCC 9999), hormaomycin (Hrm, Streptomyces griseoflavus W-384), iturin, (Itu, Bacillus amyloliquefaciens), lichenysin (Lic, B. licheniformis ATCC 10716), massetolide (Mass, $P$. fluorescens SS101), myxochromide (Mch, Stigmatella aurantiaca DW4/3-1), mycosubtilin (Myc, B. subtilis ATCC 6633), orfamide (Orf, P. protegens Pf-5), polymyxin (Pmx, Paenibacillus polymyxa E681), pristinamycin (Pri, Streptomyces pristinaespiralis SP92), putisolvin (Pso, $P$. putida PCL1445), surfactin (Srf, B. subtilis ATCC 21332), syringafactin (Syf, P. syringae DC3000), syringopeptin (Syp, P. syringae pv. syringae B301D and B728a), syringomycin (Syr, P. syringae pv. syringae strain B301D), viscosin (Visc, P. fluorescens SBW25). The TE-domains of ThfB of strains SH-C52 and DSM 11579 are indicated in blue and red, respectively.

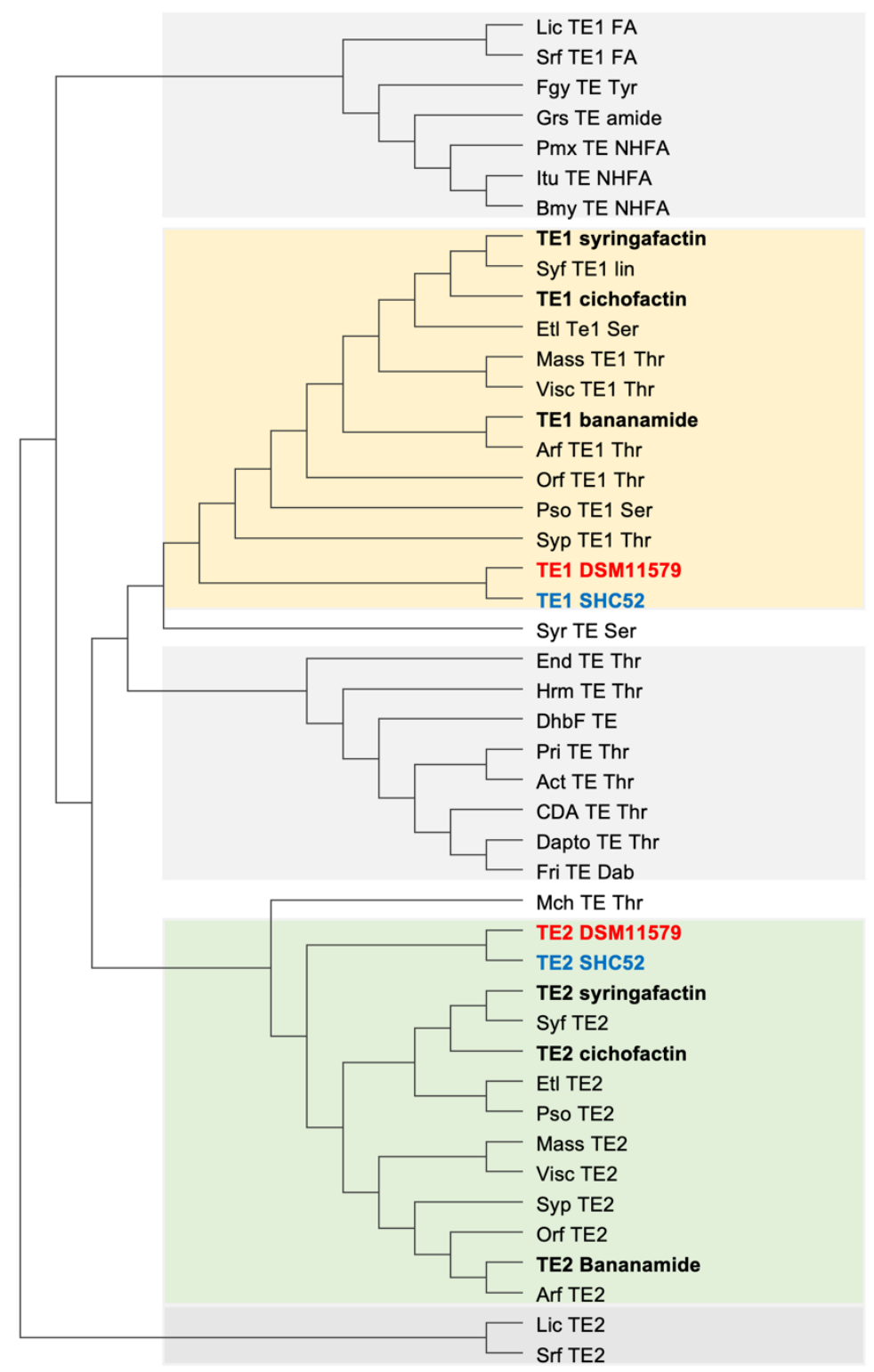

Type I TE of Bacilli macrocyclization via fatty acid

Type I TE integrated function

Type I TE of Actinomycetes macrocyclization via Thr/Dab within the peptidic moiety of the CLP

Type II TE of Pseudomonads macrocyclization via Thr/Ser within the peptidic moiety of the CLP

Type II TE repair function 
Table S5. List of primers used in this study

\begin{tabular}{|c|c|c|c|}
\hline Name & Primer (5'- - 3') & Strain & Function \\
\hline SHC52 NN fw & AAAACTCAACAGCCCAACGAACT & \multirow{2}{*}{ Pseudomonas fluorescens SH-C52 } & \multirow{2}{*}{$\begin{array}{l}\text { Determine } \\
\text { NNs in the } \\
\text { sequence }\end{array}$} \\
\hline SHC52 NN rv & AAA GAACAGGGTGCGTACATCG & & \\
\hline SHC52 NRPS fw & AAATCTAGAAACACACGGCGTTTTTCAG & \multirow{2}{*}{ Pseudomonas fluorescens SH-C52 } & \multirow[t]{2}{*}{ Disruption } \\
\hline SHC52 NRPS rv & AAAGAATTCGCTGTCGTCGAGCATGTG & & \\
\hline DSM NRPS fw & AAATCTAGAGCCTATGTGCCGCTGGAC & \multirow{2}{*}{ Pseudomonas fluorescens DSM 11579} & \multirow[t]{2}{*}{ Disruption } \\
\hline DSM NRPS rv & AAAGAATTCGGTCAGGGGCAGGGTCGG & & \\
\hline SHC52 check fw & AAATCTGTTTCACCATCTTCTGC & \multirow{2}{*}{ Pseudomonas fluorescens SH-C52 } & \multirow{2}{*}{$\begin{array}{l}\text { Check the } \\
\text { disruption }\end{array}$} \\
\hline SHC52 check rv & AAAATTTGCTCCACCAGTCCC & & \\
\hline DSM check fw & AAACTATGAGGCGCTCAATACC & \multirow{2}{*}{ Pseudomonas fluorescens DSM 11579} & \multirow{2}{*}{$\begin{array}{l}\text { Check the } \\
\text { disruption }\end{array}$} \\
\hline DSM check rv & AAAAATGATCGCTTTCCGTCT & & \\
\hline M13 fw & GTAAAACGACGGCCAGT & \multirow{2}{*}{$\begin{array}{l}\text { Pseudomonas fluorescens SH-C52 } \\
\text { Pseudomonas fluorescens DSM } 11579\end{array}$} & \multirow{2}{*}{$\begin{array}{c}\text { Check the } \\
\text { disruption and } \\
\text { sequencing }\end{array}$} \\
\hline M13 rv & CAGGAAACAGCTATGAC & & \\
\hline KanR fw & AAA TGCTCCTGCCGAGAAAGTAT & \multirow{2}{*}{$\mathrm{pCR}^{\circledR} \mathrm{Blunt}$ vector } & \multirow{2}{*}{$\begin{array}{l}\text { Kanamycin } \\
\text { resistant gene }\end{array}$} \\
\hline KanR rv & AAA AGCCAACGCTATGTCCTGAT & & \\
\hline
\end{tabular}


Figure S6. Comparative HPLC profiles of the crude extracts of the SH-C52 and DSM 11579 wt strains vs. two corresponding $\mathrm{mt}$ strains of each strain. The chromatograms show the UV traces at $210 \mathrm{~nm}$, extracted from the LC-MS runs.

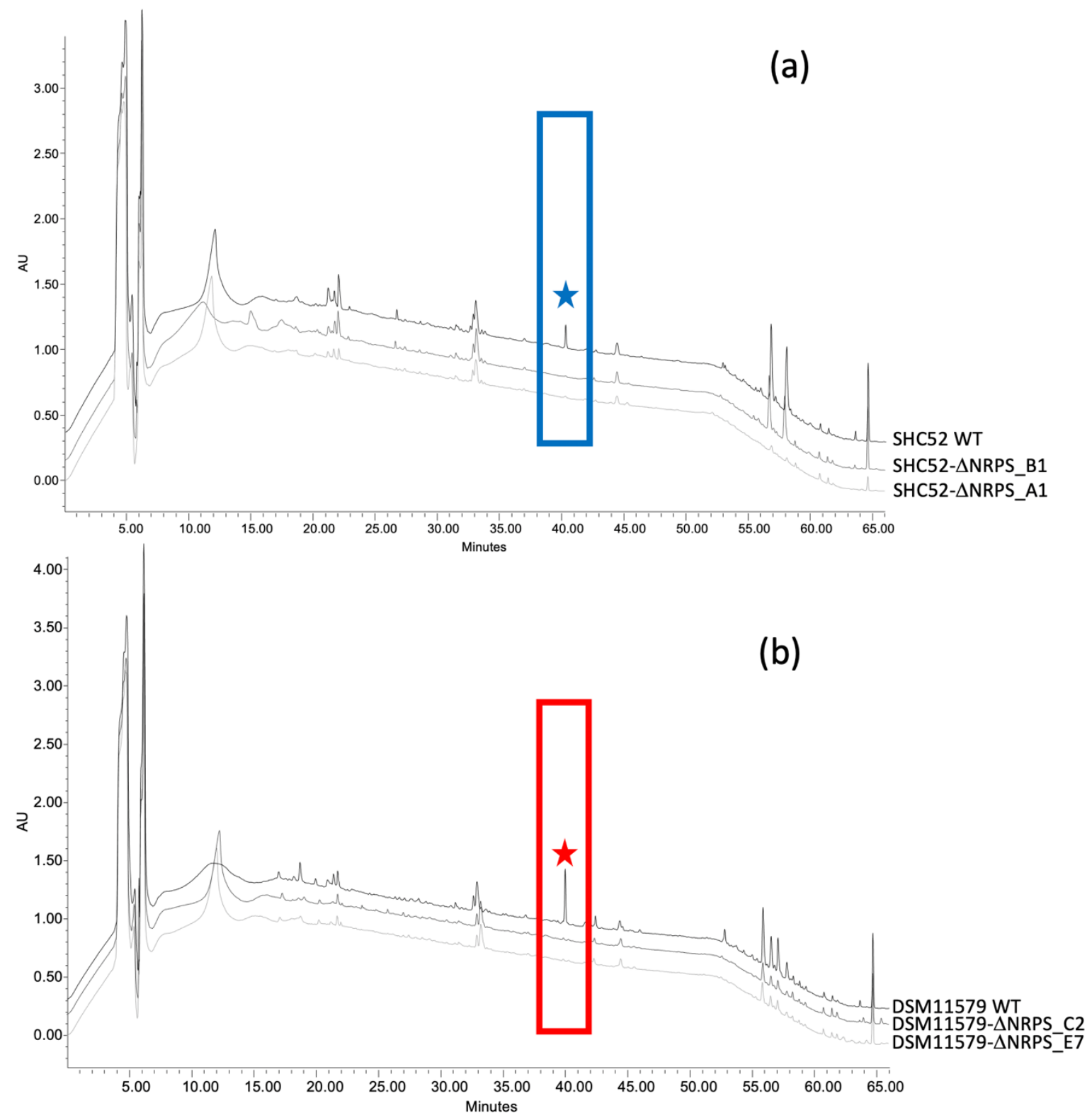


Figure S7. HPLC run of the crude Diaion HP-20 extract from an upscaled cultivation batch of the DSM 11579 strain.

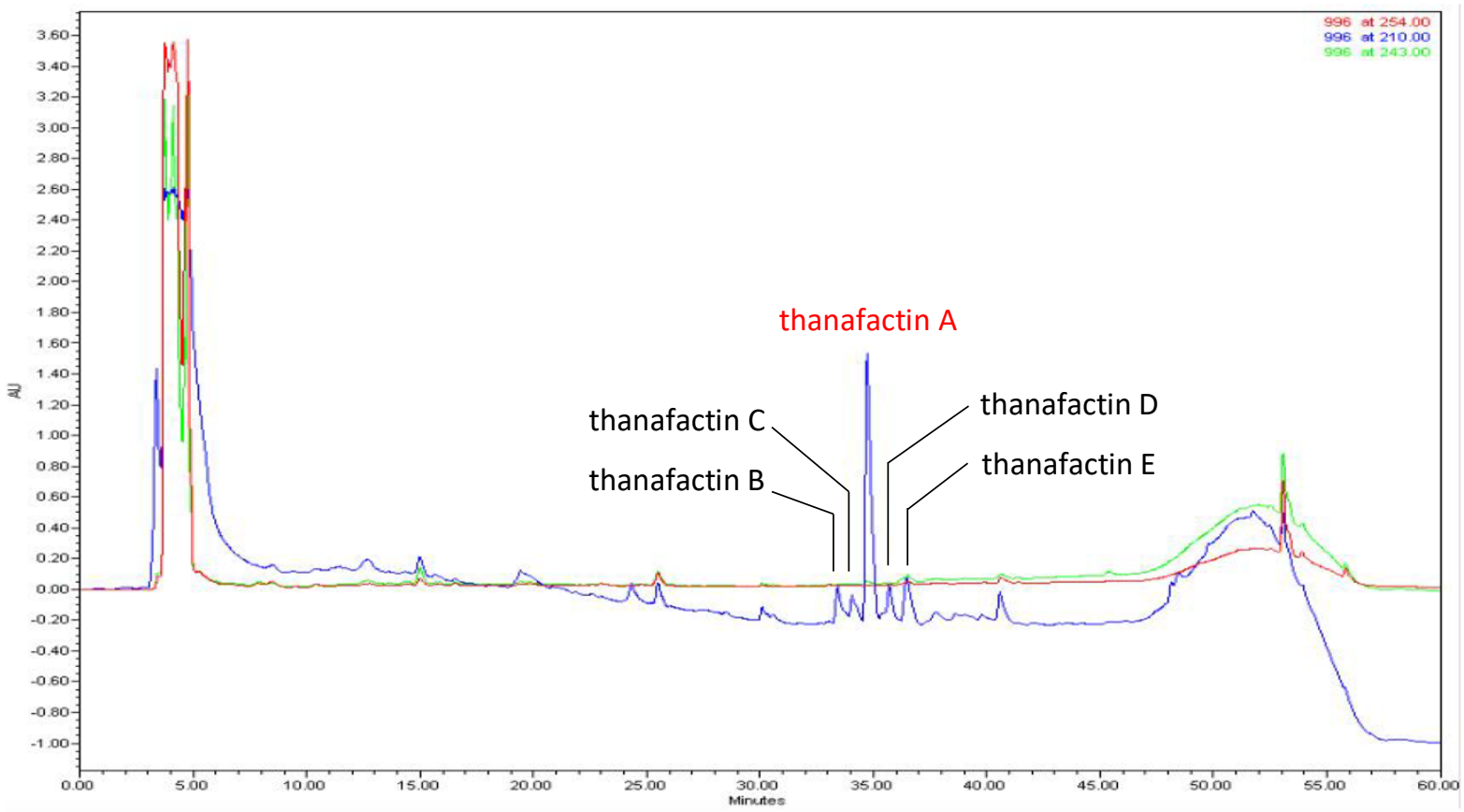

Spectral Data for Thanafactin A (1)

Figure S8. HR-ESI-MS spectrum of $\mathbf{1}$ (positive mode).

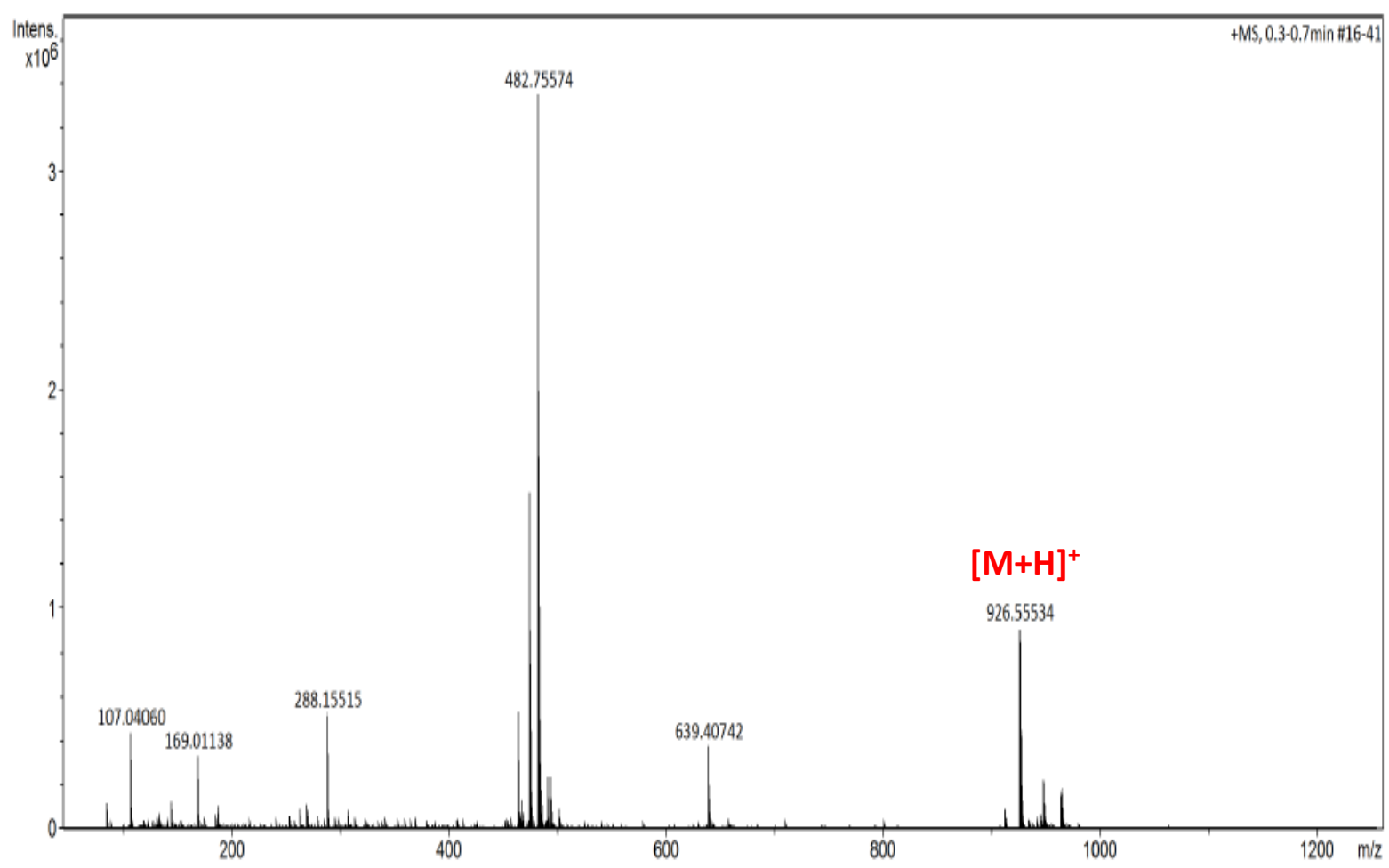


Figure 59. UV spectrum of 1 in $\mathrm{MeOH}$.

Thanafactin A (1) shows only end-absorption at $204 \mathrm{~nm}$.

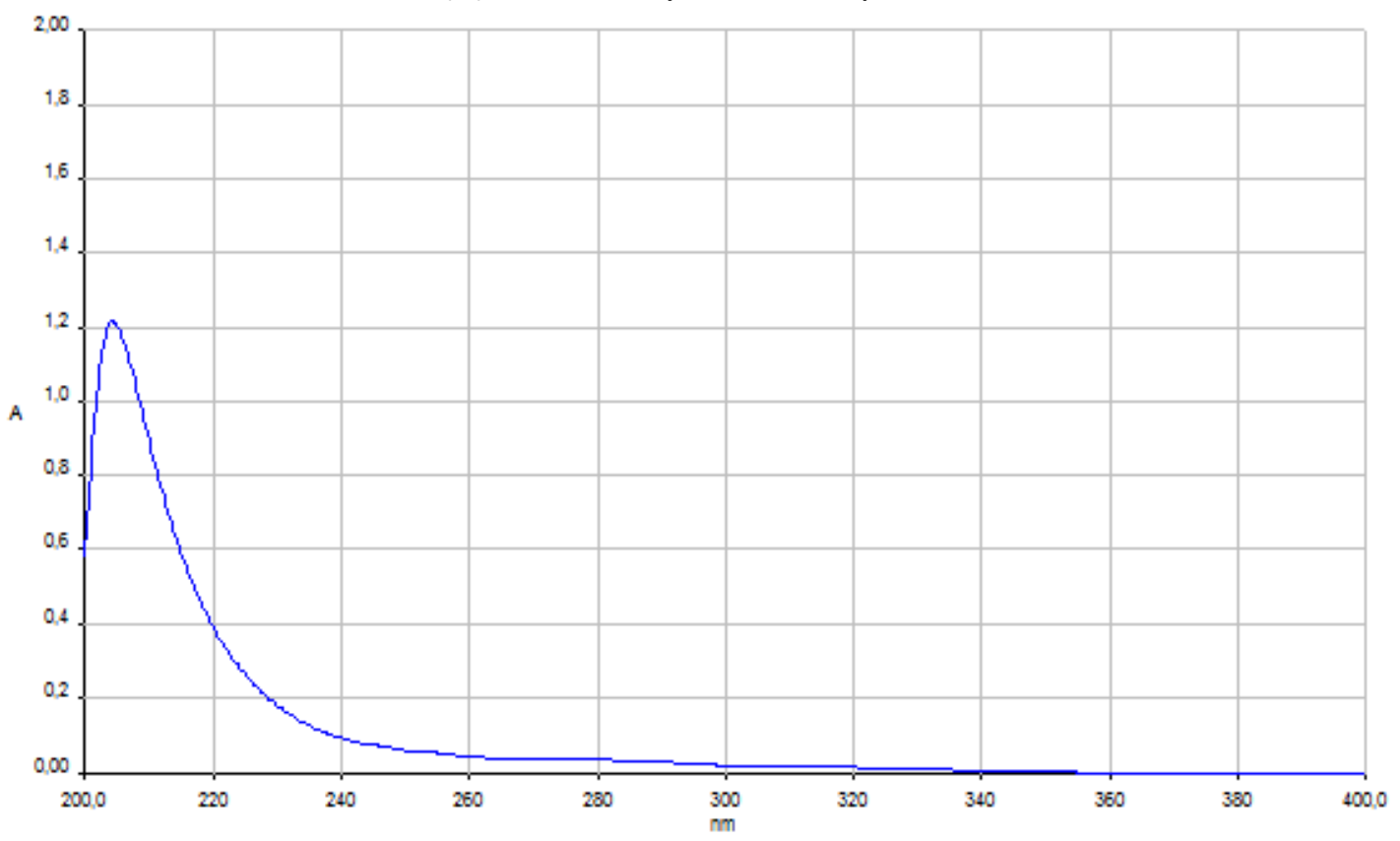

Figure S10. CD-spectrum of 1 in $\mathrm{MeOH}$.

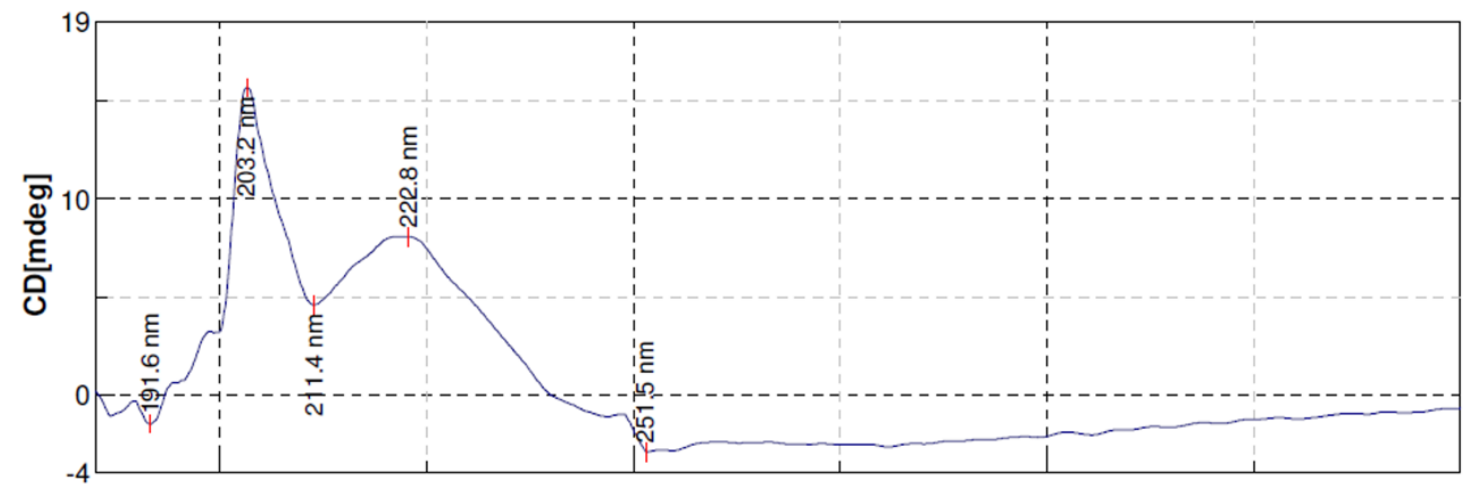


Figure S11. FT-IR spectrum of 1.

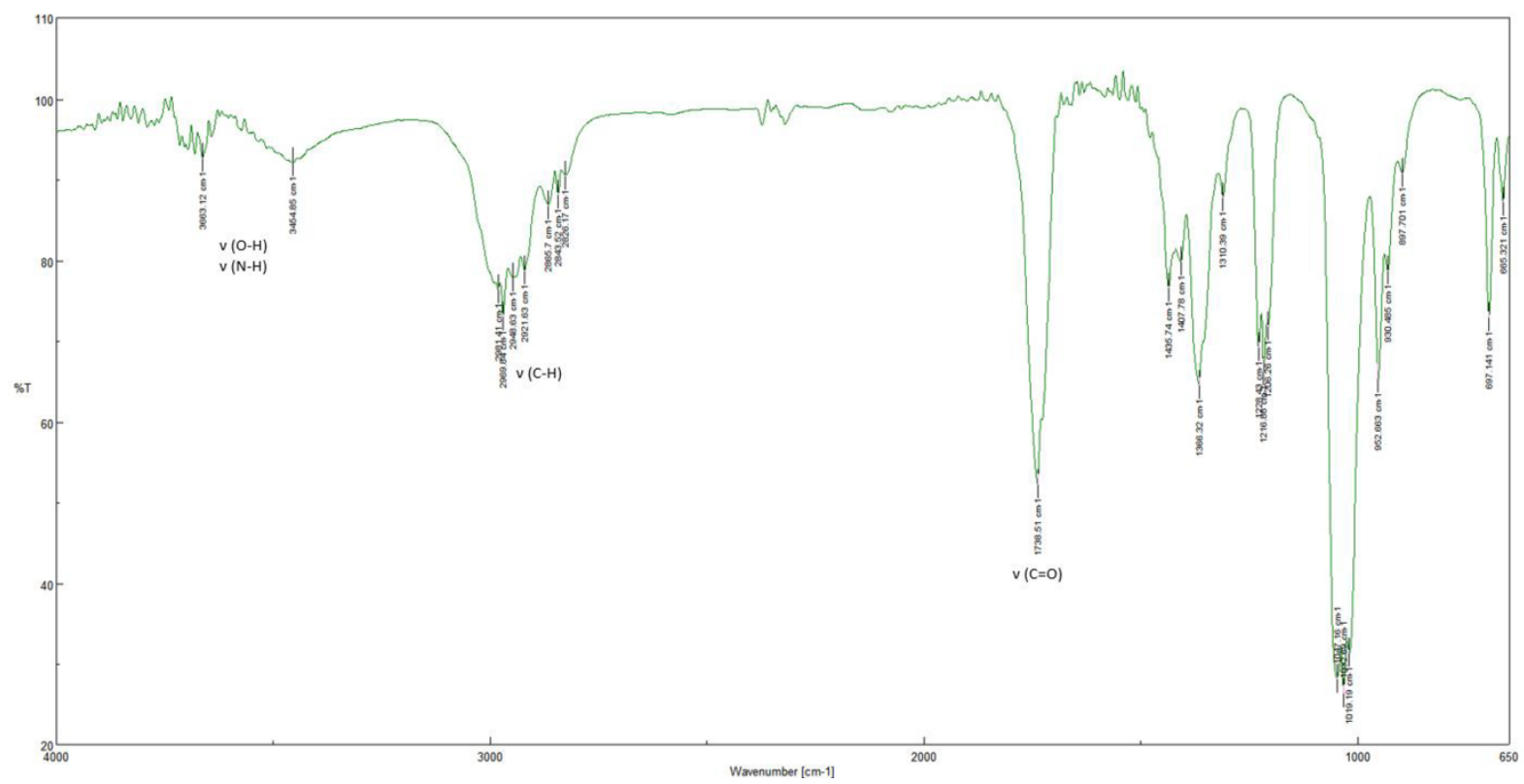

Figure S12. $400 \mathrm{MHz}{ }^{1} \mathrm{H}$ NMR spectrum of 1 in $d_{6}$-DMSO.

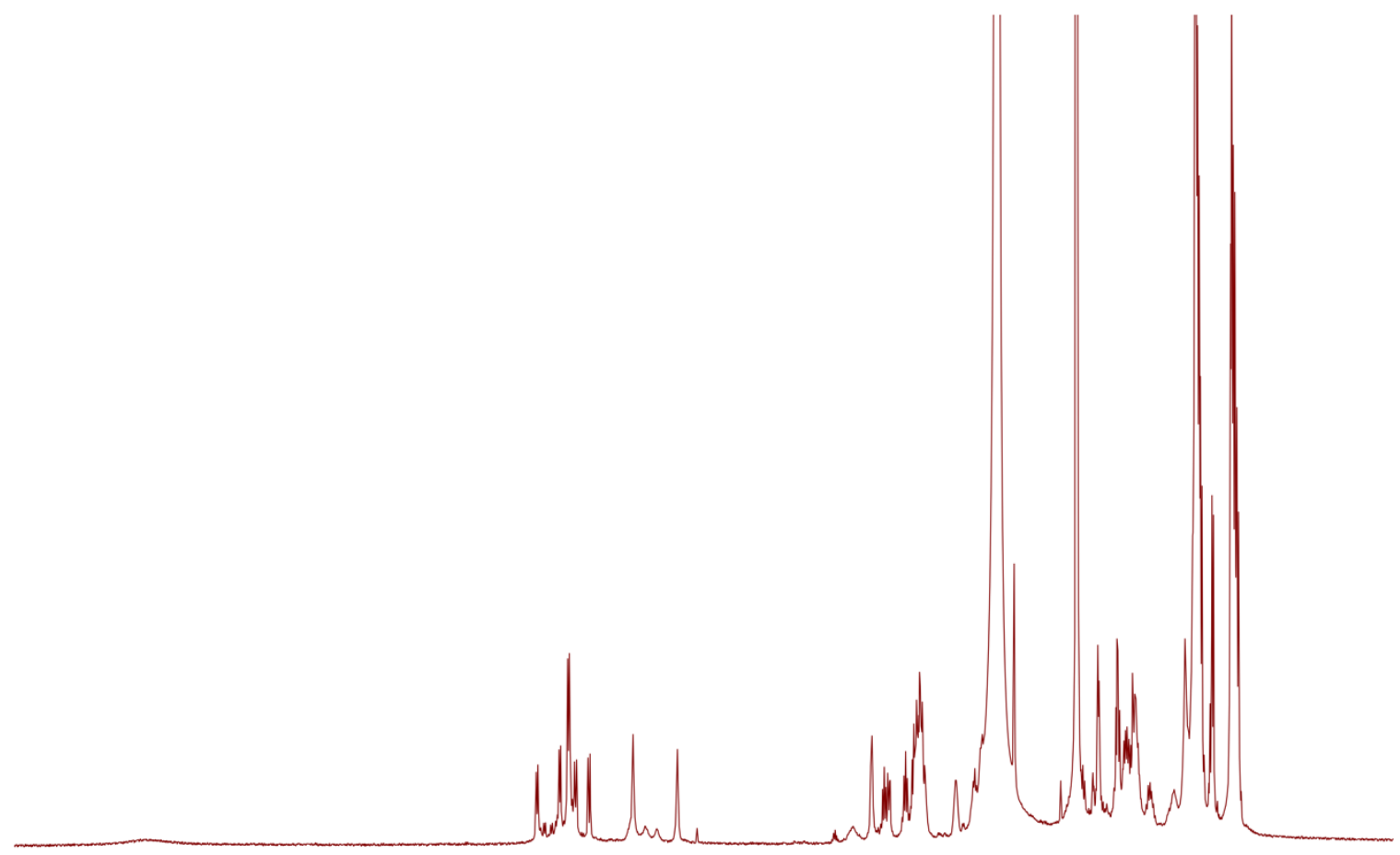

$\begin{array}{llllllllllllllllllllllllllllllllllllll}13.5 & 13.0 & 12.5 & 12.0 & 11.5 & 11.0 & 10.5 & 10.0 & 9.5 & 9.0 & 8.5 & 8.0 & 7.5 & 7.0 & 6.5 & 6.0 & 5.5 & 5.0 & 4.5 & 4.0 & 3.5 & 3.0 & 2.5 & 2.0 & 1.5 & 1.0 & 0.5 & 0.0 & -0.5\end{array}$ 
Figure S13. $100 \mathrm{MHz}{ }^{13} \mathrm{C}$ NMR spectrum of 1 in $d_{6}$-DMSO.

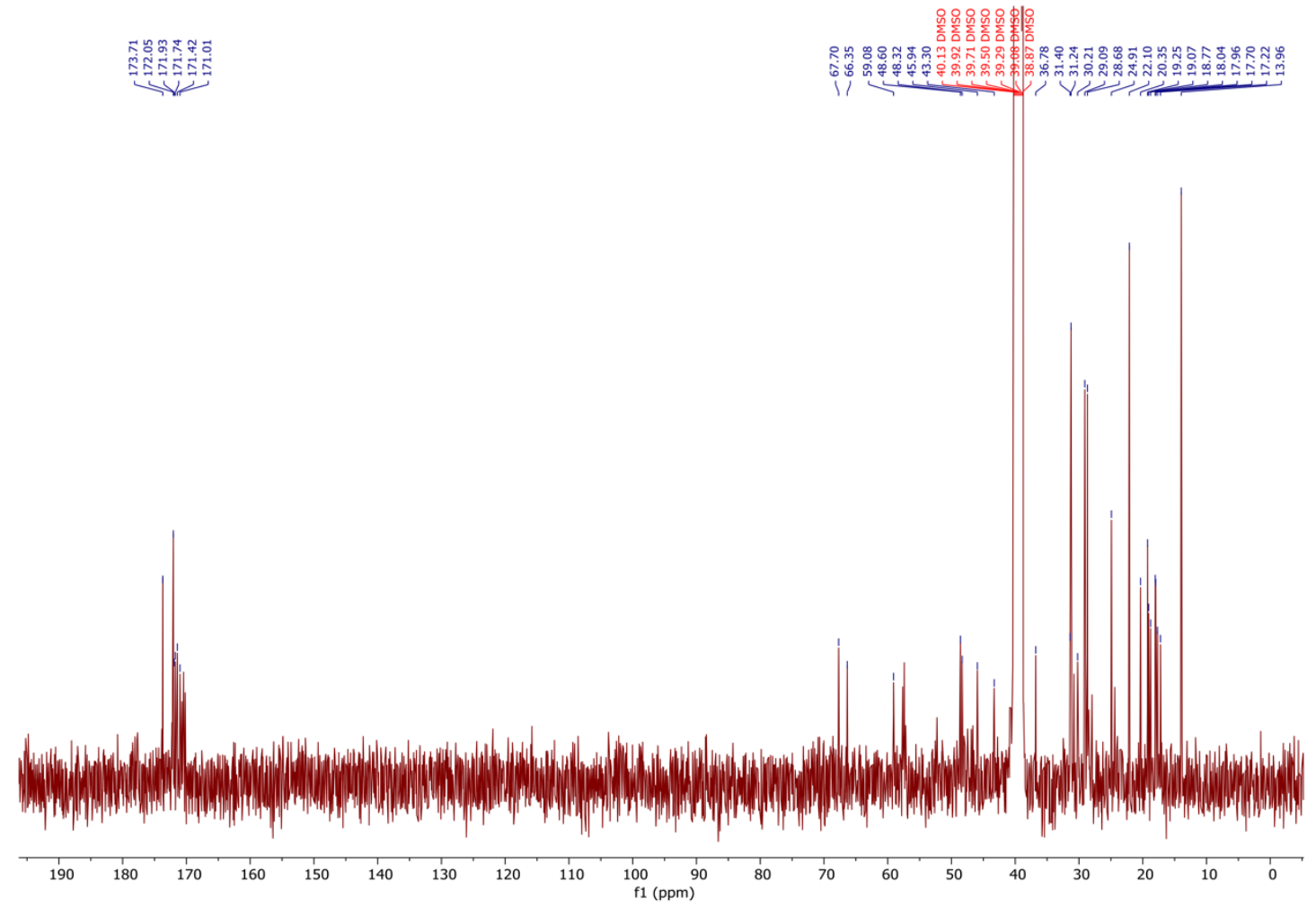

Figure S13a. Detail region (12-32 ppm) of the $100 \mathrm{MHz}{ }^{13} \mathrm{C}$ NMR spectra of 1 in $d_{6}$-DMSO.

\begin{tabular}{|c|c|}
\hline 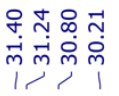 & 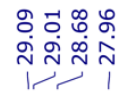 \\
\hline
\end{tabular}
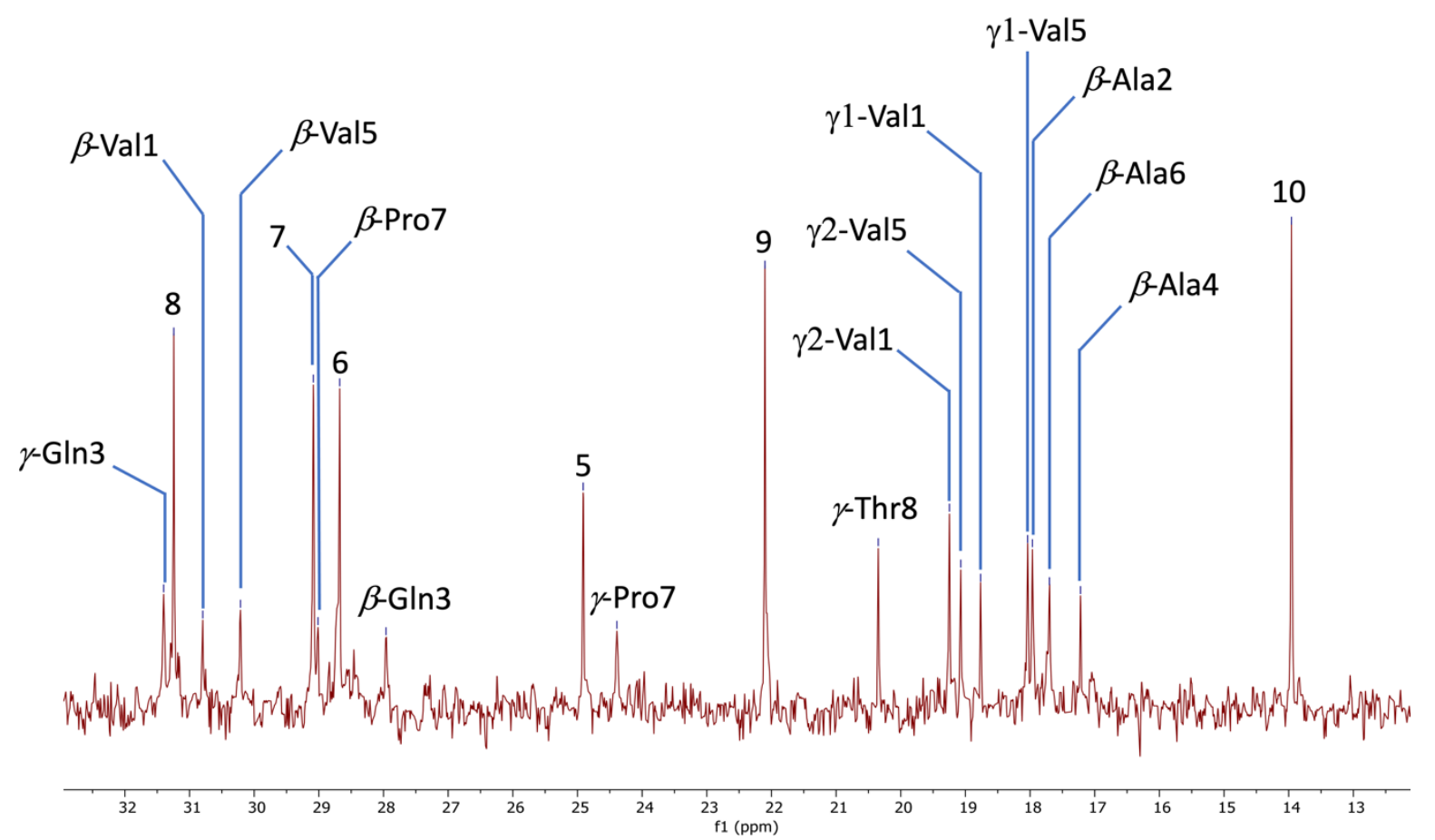
Figure S13b. Detail region (34-71 ppm) of the $100 \mathrm{MHz}{ }^{13} \mathrm{C}$ NMR spectra of 1 in $d_{6}$-DMSO.

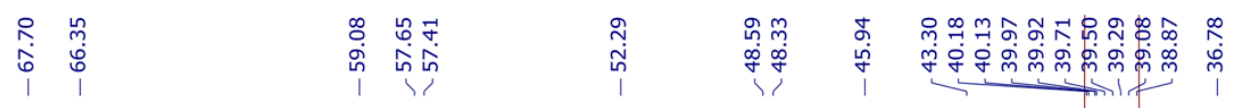

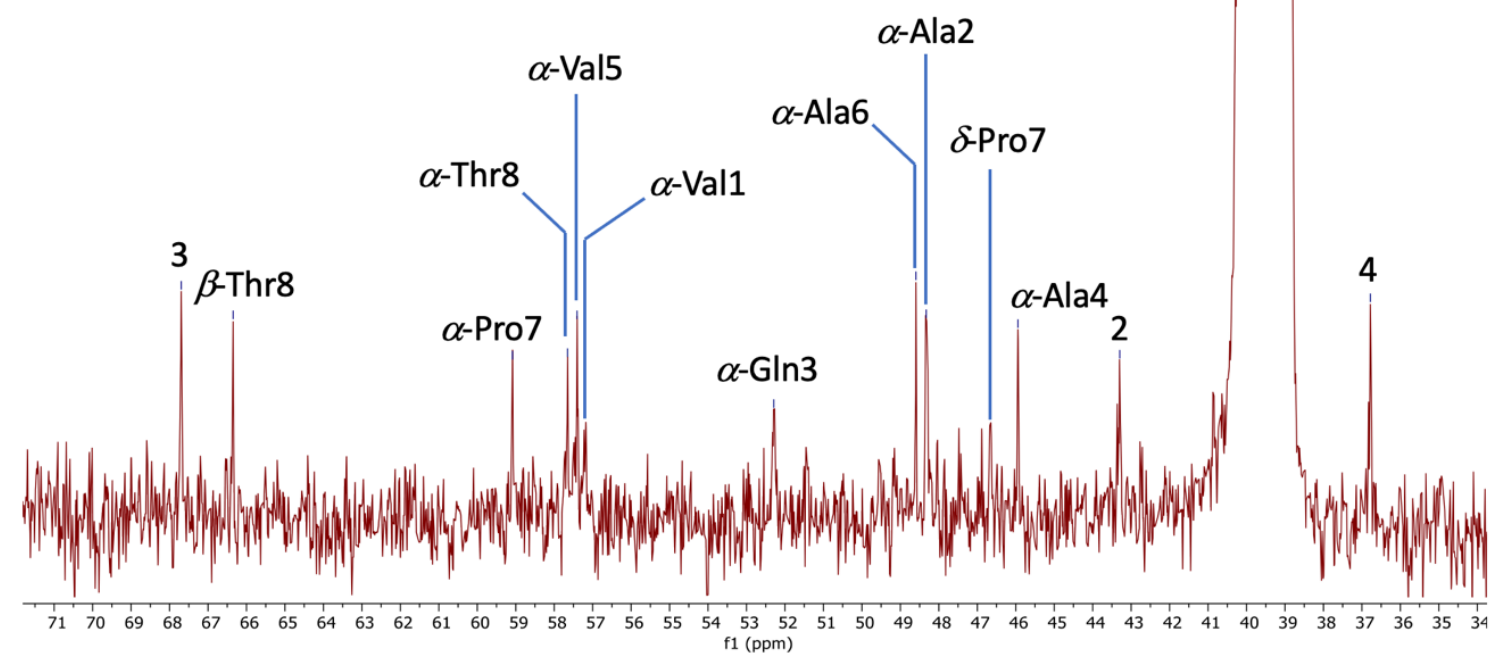

Figure S13c. Detail region (166-177 ppm) of the $100 \mathrm{MHz}{ }^{13} \mathrm{C}$ NMR spectra of 1 in $d_{6}$-DMSO.

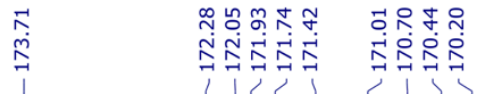

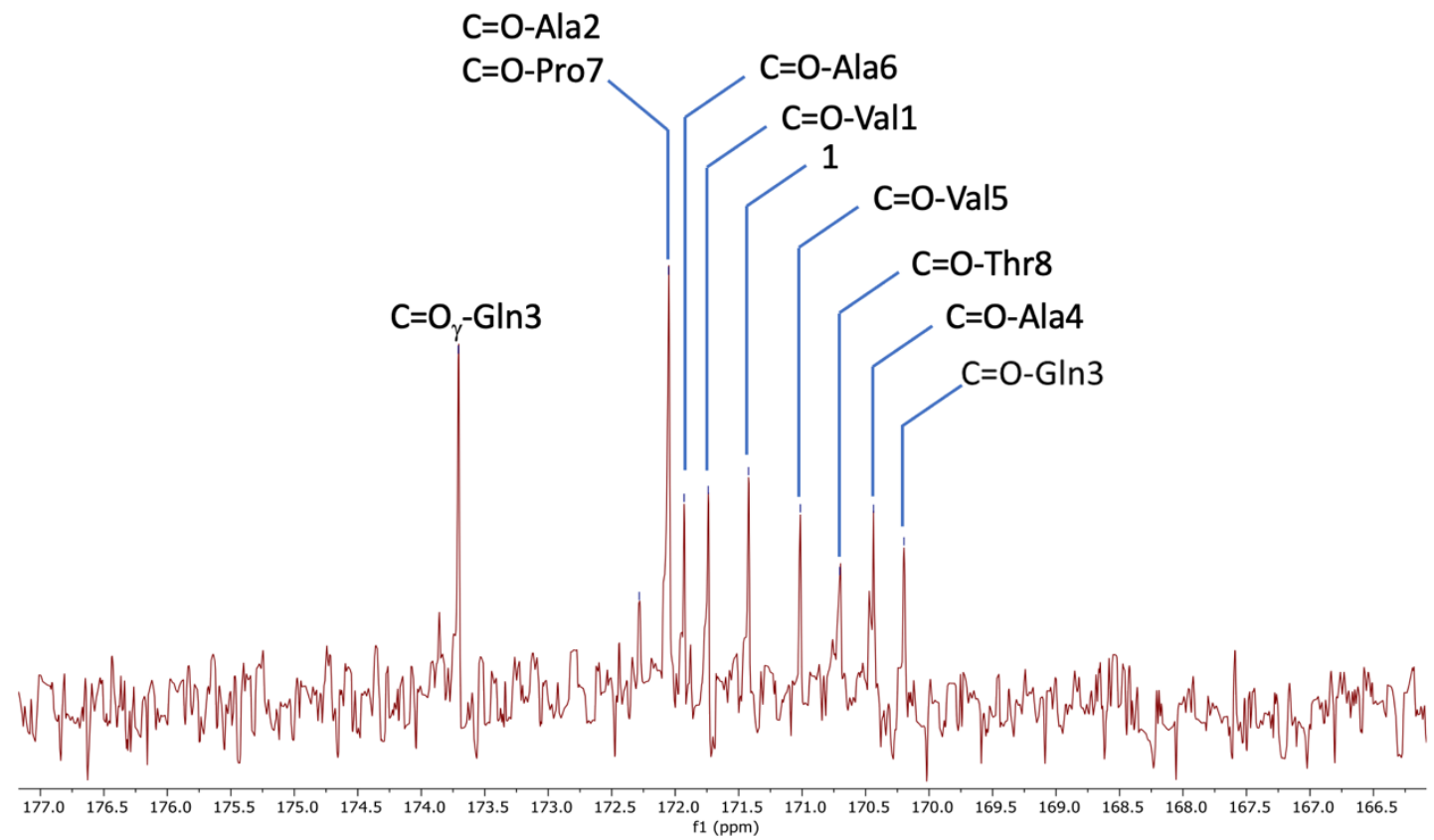


Figure S14. $400 \mathrm{MHz}$ DEPT135 NMR spectrum of 1 in $d_{6}$-DMSO.

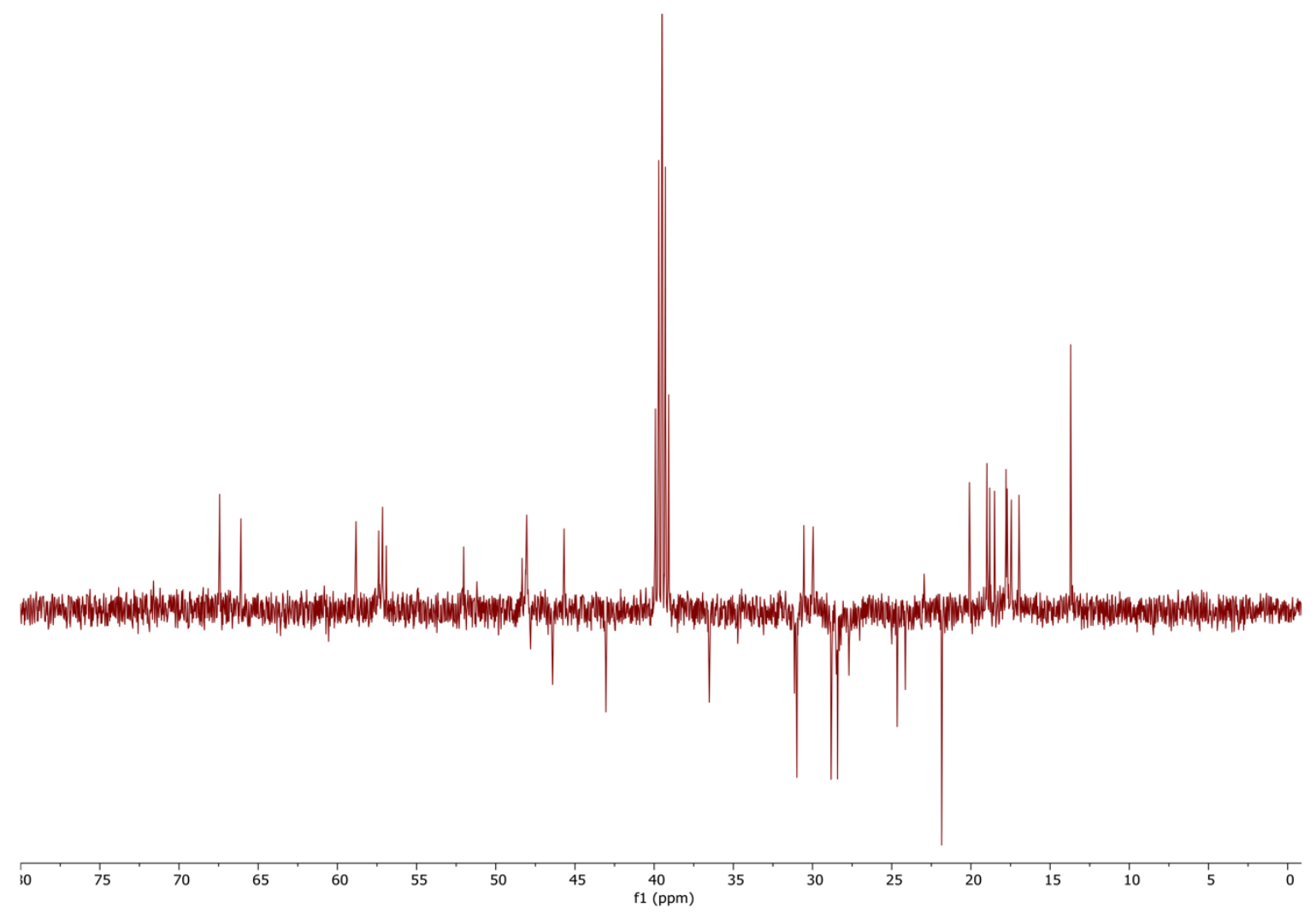


Figure $\mathbf{S 1 5 .} 400 \mathrm{MHz}{ }^{1} \mathrm{H}_{-}{ }^{13} \mathrm{C}$ HSQC NMR spectrum of 1 in $d_{6}$-DMSO.

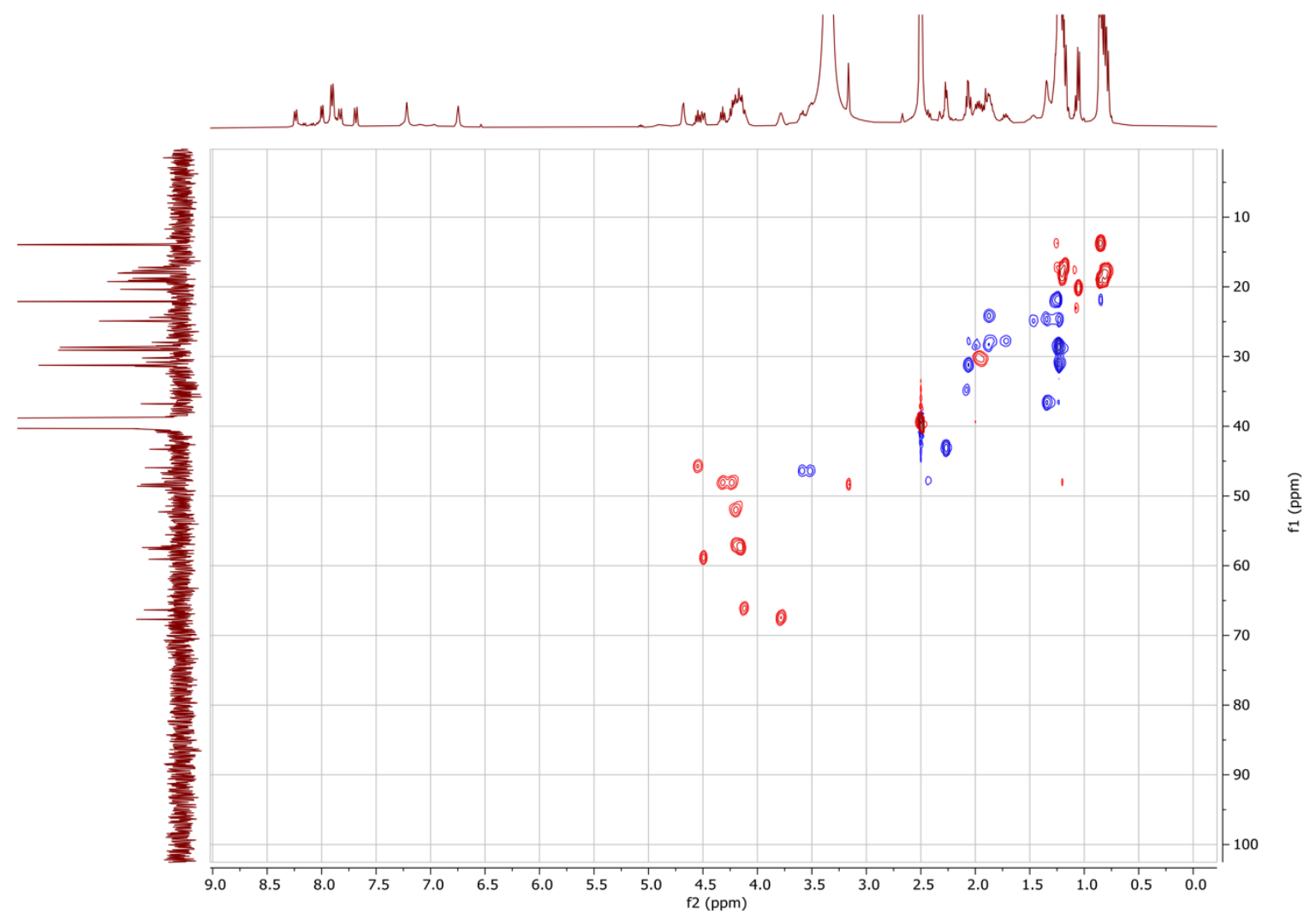

Figure S16. $400 \mathrm{MHz}{ }^{1} \mathrm{H}_{-}{ }^{1} \mathrm{H}$ COSY NMR spectrum of 1 in $d_{6}$-DMSO.

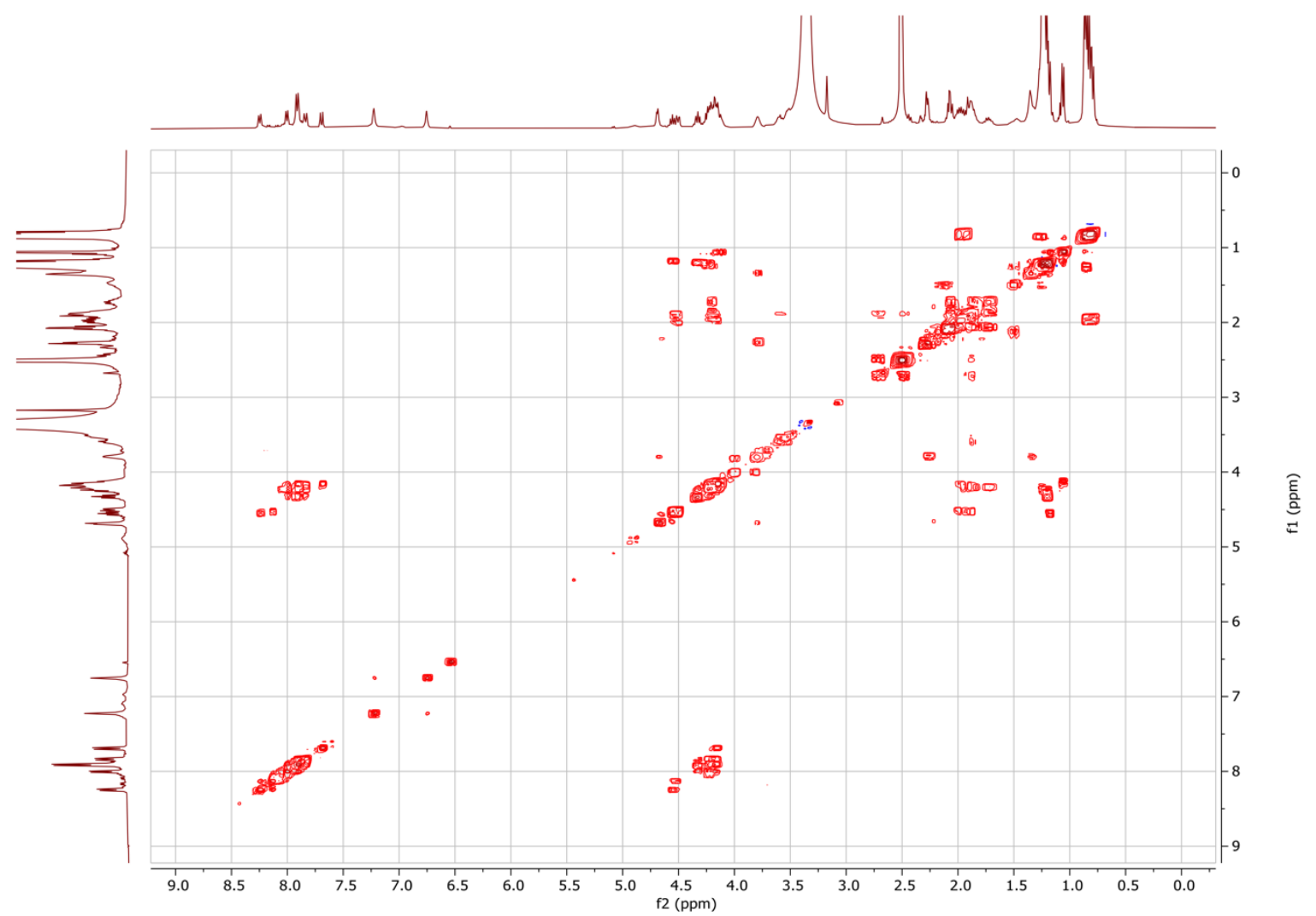


Figure S17. $400 \mathrm{MHz}{ }^{1} \mathrm{H}_{-}{ }^{13} \mathrm{C}$ HSQC-TOCSY NMR spectrum of 1 in $d_{6}$-DMSO. Purple box shows an expansion of the $\alpha$-hydrogen region.

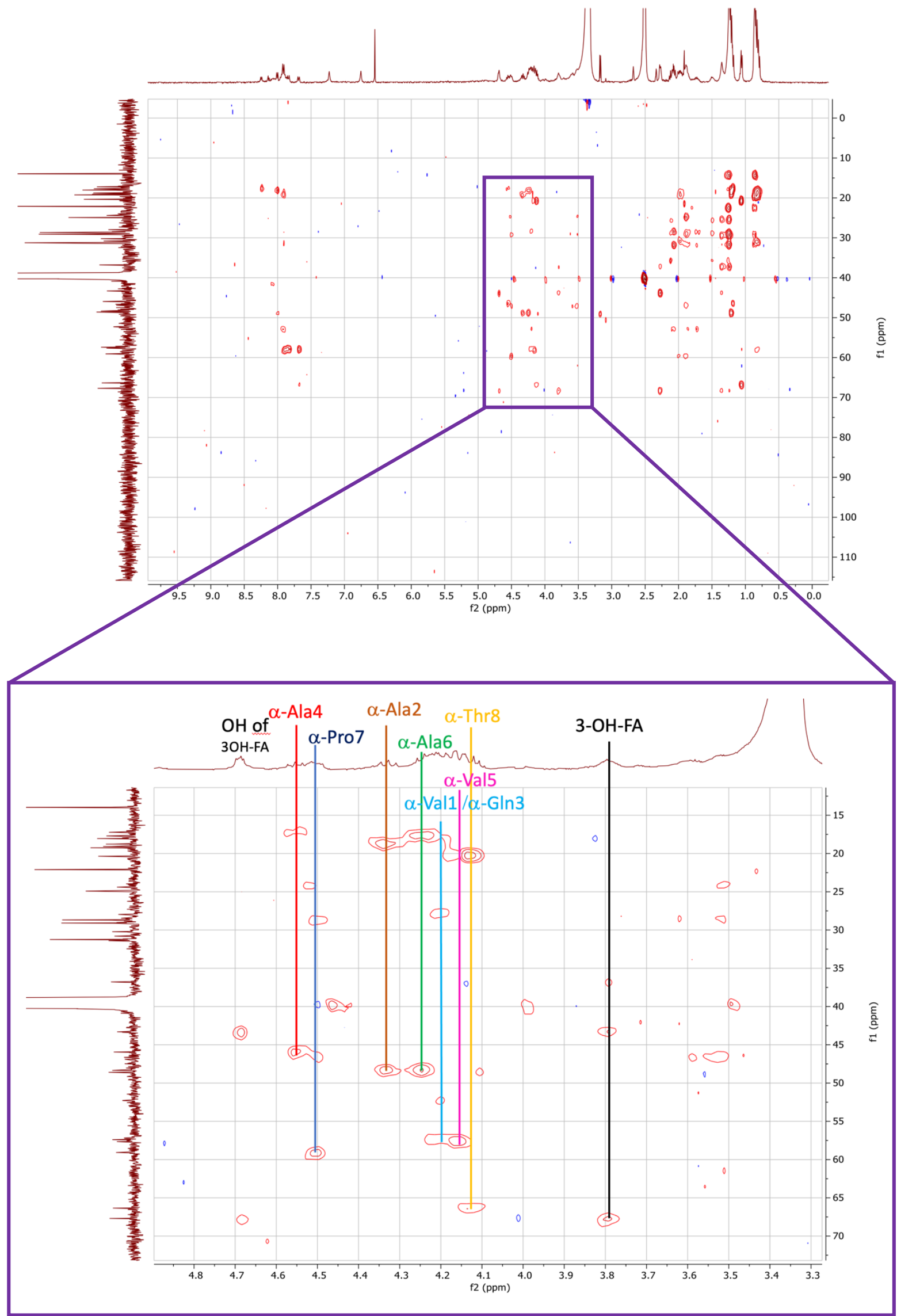


Figure S18. MS/MS spectrum of 1 (top). Bottom scheme shows the corresponding fragmentation pattern; the theoretical $b$ - and $y$-ion series are indicated in black, while the observed ions (solely $b$-ions) are indicated in red.
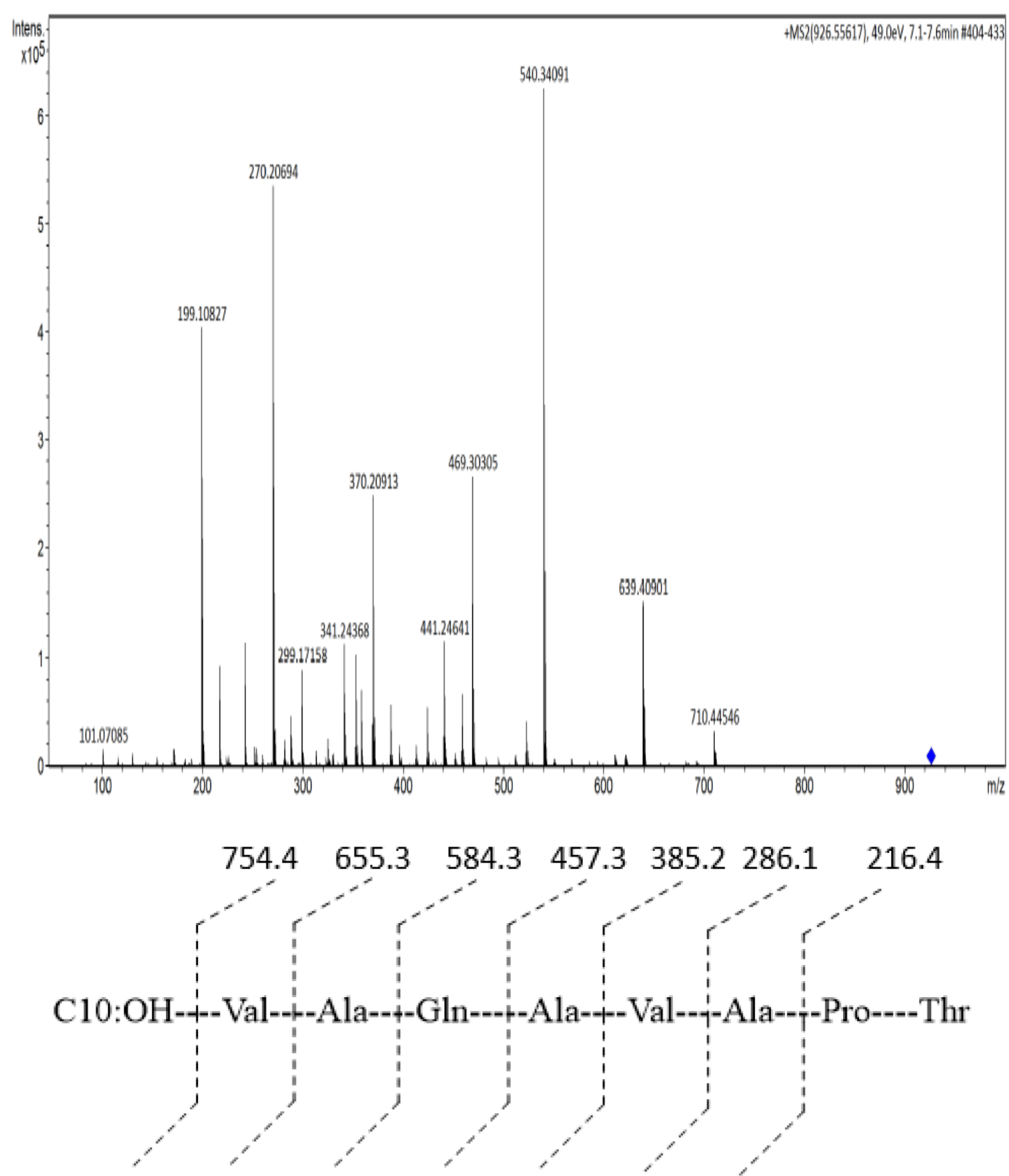

$\begin{array}{lllllll}171.1 & 270.2 & 341.2 & 469.3 & 540.3 & 639.4 & 710.5\end{array}$ 
Figure S19. Determination of the absolute configuration of 3-HDA of 1

3-Hydroxydecanoic acid was extracted from a thanafactin peptide hydrolysate $\left(6 \mathrm{~N} \mathrm{DCl} / \mathrm{D}_{2} \mathrm{O}\right.$, $18 \mathrm{~h}, 110^{\circ} \mathrm{C}$ ) using chloroform. After chloroform removal, residue was dissolved in methanol and analyzed on the chiral phase Chirasilpak (a) ZWIX (+) and (b) ZWIX (-) columns (150 x 4 $\mathrm{mm} ; 3 \mu \mathrm{m})$, using $\mathrm{ACN}: \mathrm{MeOH}: \mathrm{AcOH}(95: 5: 0.025 ; \mathrm{v} / \mathrm{v} / \mathrm{v})$ as mobile phase at a flow rate of 300 $\mu \mathrm{L} / \mathrm{min}$ and $5{ }^{\circ} \mathrm{C}$ column temperature. The QTOF-ESI-MS instrument was operated in negative ionization mode. Extracted ion chromatograms of the TOF runs ([3-HDA - H] $]^{-}: 187.1340 \pm$ $0.010 \mathrm{~m} / \mathrm{z}$ extraction window) are shown above.
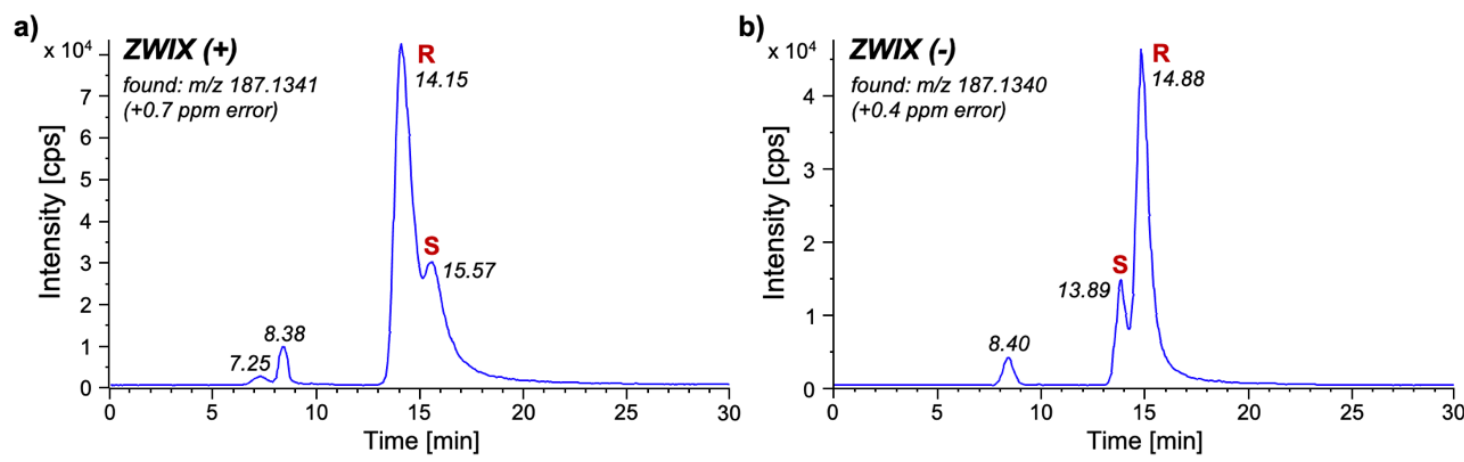
Figure S20. Enantioselective GC-MS analysis of the peptide hydrolysate of thanafactin A.

Chiral amino acid composition of peptide thanafactin $A$ was determined on a chiral phase Chiralpak ZWIX(+) column (150 mm x $4 \mathrm{~mm}, 3 \mu \mathrm{m})$ after acidic hydrolysis ( $18 \mathrm{~h} 6 \mathrm{~N} \mathrm{DCl}$ in $\mathrm{D}_{2} \mathrm{O}$ ) and derivatization with 6-aminoquinolyl-H-hydroxysuccinimidyl carbamate (AQC; 10 min at 55 $\left.{ }^{\circ} \mathrm{C}\right)$. The LC-QTOF-ESI-MS was operated in positive ionization mode. Extracted ion chromatograms of above shown amino acids were generated with an extraction window width of $m / z$ 0.020. Hse: Homoserine (syn. isothreonine).
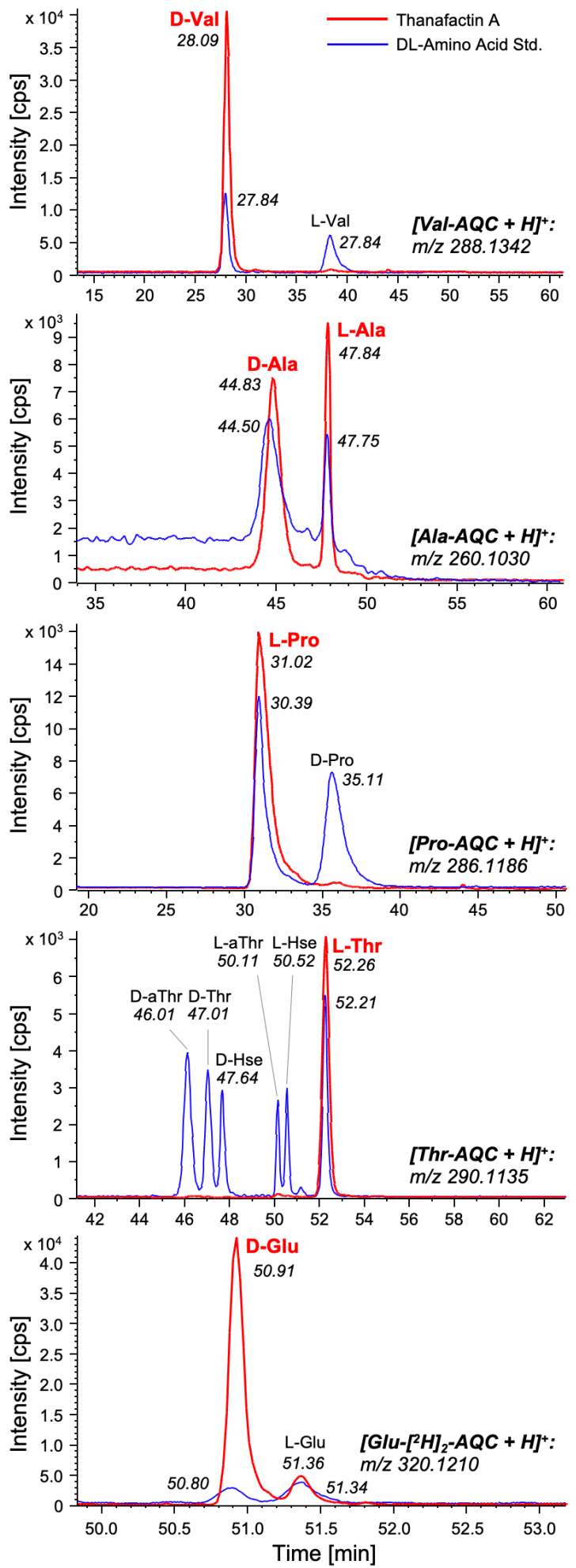


\section{Bioassay data}

Figure S21. Swarming Assays

Pseudomonas sp. SH-C52
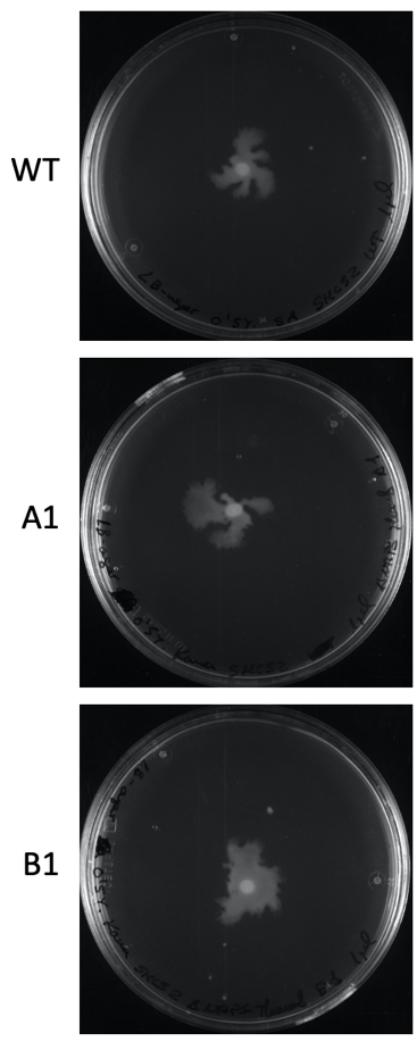

$1 \mu \mathrm{l}$

$5 \mu \mathrm{l}$
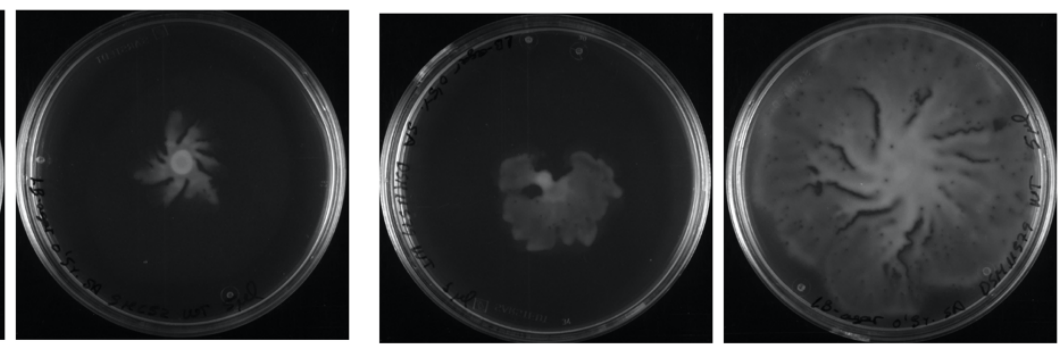

WT
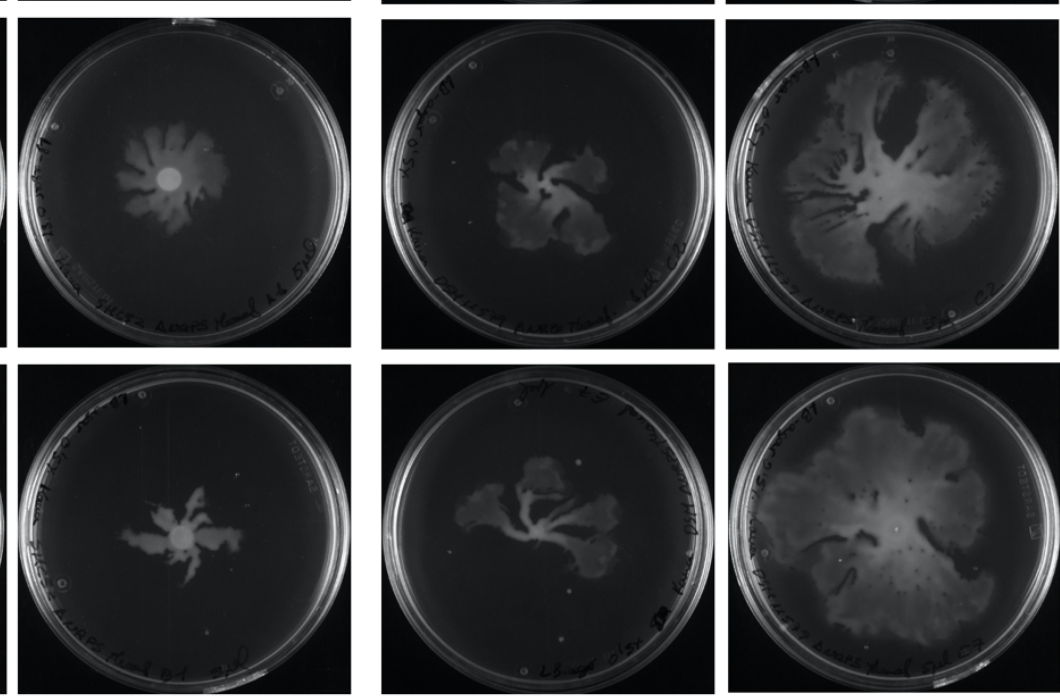

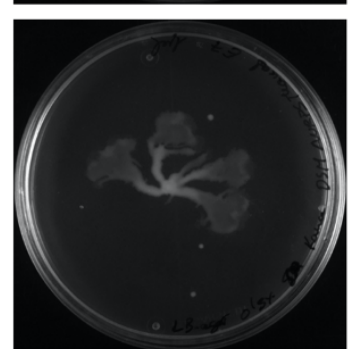

$1 \mu \mathrm{l}$

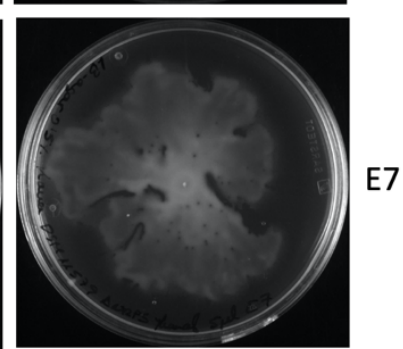

$5 \mu \mathrm{l}$

Table S6. Protease inhibition assay.

\begin{tabular}{|l|c|c|c|}
\hline Protease & Substrate & $\begin{array}{c}{[\text { Thanafactin] }} \\
(\mu \mathrm{M})\end{array}$ & $\begin{array}{c}\text { Activity } \\
(\%)^{\text {a }}\end{array}$ \\
\hline Human cathepsin K & Z-Leu-Arg-AMC & 10 & 79.9 \\
\hline Human cathepsin B & Z-Arg-Arg-pNA & 10 & n.i. \\
\hline Human cathepsin L & Z-Phe-Arg-pNA & 10 & n.i. \\
\hline Human leukocyte elastase & MeO-Suc-Ala-Ala-Pro-Val-pNA & 10 & n.i. \\
\hline Human thrombin & Z-Gly-Gly-Arg-AMC & 10 & n.i. \\
\hline Human matriptase-2 & Boc-Gln-Ala-Arg-AMC & 10 & n.i. \\
\hline Bovine chymotrypsin & Suc-Ala-Ala-Pro-Phe-pNA & 10 & n.i. \\
\hline Bovine trypsin & Suc-Ala-Ala-Pro-Arg-pNA & 10 & n.i. \\
\hline Bovine factor Xa & Boc-Ile-Glu-Gly-Arg-AMC & 10 & n.i. \\
\hline Porcine pancreatic elastase & MeO-Suc-Ala-Ala-Pro-Val-pNA & 10 & n.i. \\
\hline
\end{tabular}

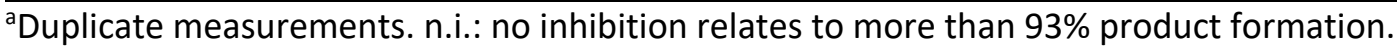

